\title{
Lactobacillus Rhamnosus HDB1258 Modulates Gut Microbiota-Mediated Immune Response in Mice with or Without LPS-Induced Systemic Inflammation
}

\section{Sang-Kap Han}

Kyung Hee University

Yeon-Jeong Shin

Kyung Hee University

Dong-Yeon Lee

Kyung Hee University

Kyung Min Kim

HYUNDAI Bioland Co

Seo-Jin Yang

HYUNDAI Bioland Co

Du Seong Kim

HYUNDAI Bioland Co

Ji-Whi Choi

HYUNDAI Bioland Co

Seunghun Lee

HYUNDAI Bioland Co

Dong-Hyun Kim ( $\nabla$ dhkim@khu.ac.kr)

Kyung Hee University

\section{Research Article}

Keywords: Lactobacillus rhamnosus HDB1258, immunomodulation, immune enhancement, 51 inflammation, gut microbiota

Posted Date: December 3rd, 2020

DOl: https://doi.org/10.21203/rs.3.rs-112385/v1

License: (c) (1) This work is licensed under a Creative Commons Attribution 4.0 International License.

Read Full License 
1 [BMC Microbiology]

2

Lactobacillus rhamnosus HDB1258 modulates gut microbiota-mediated immune response in mice with or without LPS-induced systemic inflammation

5

6 Sang-Kap Han ${ }^{1, \#}$, Yeon-Jeong Shin ${ }^{1, \#}$, Dong-Yeon Lee ${ }^{1}$, Kyung Min Kim² ${ }^{2}$, Seo-Jin Yang ${ }^{2}$, Du Seong Kim², Ji-Whi Choi ${ }^{2}$, Seunghun Lee ${ }^{2}$ and Dong-Hyun Kim ${ }^{1, *}$

8

9

${ }^{1}$ Neurobiota Research Center, College of Pharmacy, Kyung Hee University, Kyungheedae-ro, Dongdaemun-gu, Seoul 02447, Korea; ${ }^{2}$ HYUNDAI Bioland Co., Ltd., Ansan 15407, Korea

\#Equally contributed

*Correspondence: dhkim@khu.ac.kr

Neurobiota Research Center, College of Pharmacy, Kyung Hee University, 


\section{Abstract:}

\section{Background}

Gut microbiota closely communicate in the immune system to maintain a balanced immune homeostasis in the gastrointestinal tract of the host. Oral administration of probiotics modulates gut microbiota composition. In the present study, we isolated Lactobacillus rhamnosus HDB1258, which induced tumor necrosis factor (TNF)- $\alpha$ and interleukin (IL)-10 expression in macrophages, from the feces of breastfeeding infants and examined how HDB1258 could regulate the homeostatic immune response in mice with or without lipopolysaccharide (LPS)induced systemic inflammation.

\section{Results}

Oral administration of HDB1258 significantly increased splenic NK cell cytotoxicity, peritoneal macrophage phagocytosis, splenic and colonic TNF- $\alpha$ expression, TNF- $\alpha$ to IL-10 expression ratio, and fecal IgA level in control mice, while Th1 and Treg cell differentiation was not affected in the spleen. However, HDB1258 treatment significantly suppressed peritoneal macrophage phagocytosis and blood prostaglandin E2 level in mice with LPSinduced systemic inflammation. Its treatment increased LPS-suppressed ratios of Treg to Th1 cell population, Foxp3 to T-bet expression, and IL-10 to TNF- $\alpha$ expression. Oral administration of HDB1258 significantly decreased LPS-induced colon shortening, myeloperoxidase activity and $\mathrm{NF}-\mathrm{\kappa B}^{+} / \mathrm{CD} 11 \mathrm{c}^{+}$cell population in the colon, while the ratio of IL-10 to TNF- $\alpha$ expression increased. Moreover, HDB1258 treatment shifted gut microbiota composition in mice with and without LPS-induced systemic inflammation: it increased the Cyanobacteria and 
41 EU622763_s group (belonging to Bacteroidetes) populations. In particular, PAC001066_g and 42 PAC001072_s populations were negatively correlated with the ratio of IL-10 to TNF- $\alpha$ 43 expression in the colon, while the PAC001070_s group population was positively correlated.

45 Conclusions

46 Oral administered HDB1258 may enhance the immune response by activating innate immunity 47 including to macrophage phagocytosis and NK cell cytotoxicity in the healthy host and 48 suppress systemic inflammation in the host with inflammation by the modulation of gut 49 microbiota and IL-10 to TNF- $\alpha$ expression ratio in immune cells.

50

51 Keywords: Lactobacillus rhamnosus HDB1258; immunomodulation; immune enhancement; 52 inflammation; gut microbiota. 
Gut microbiota closely communicate in the immune system to maintain a balanced immune homeostasis in the gastrointestinal tract of the host [1,2]. The alteration of gut microbiota by exposure to gastrointestinal environmental factors such as stress, pathogens, and probiotics cause the immune system of the gastrointestinal tract to fluctuate [3]. This exposure stimulates the secretion of proinflammatory and anti-inflammatory cytokines such as tumor necrosis factor (TNF)- $\alpha$ and interleukin (IL)-10 in the immune cells, $>70 \%$ of which are located in the gut $[4,5]$. These secreted cytokines regulate the immune system consisting of innate and adaptive immune systems. The activation of innate immune cells, which consist of phagocytic leukocytes and natural killer (NK) cells, by microbes stimulates the adaptive immune cells, which consist of $\mathrm{T}$ and $\mathrm{B}$ cells, through the regulation of cytokine expression $[5,6]$. The secretion of cytokines such as TNF- $\alpha$ and IL-10 in innate immune cells by the stimulation of pathogens promotes the differentiation of naïve $\mathrm{T}$ cells into effector $\mathrm{T}$ cells such as helper $\mathrm{T}$ (Th) and regulatory $\mathrm{T}$ (Treg) cells $[7,8]$. A wide imbalance between innate and adaptive immune systems, such as hyperimmunopotentiation and immunosuppression, is a high-risk factor for the outbreak of infectious diseases, chronic inflammation, autoimmunity, and cancers $[9,10]$. Therefore, regulating the immune response in the gut may be beneficial for the therapy of peripheral and systemic immune disorders.

Probiotics including Lactobacilli, which are commonly found in fermented foods such as yogurt and kimchi and the gut microflora of humans and animals, exhibit the beneficial physiological activities including the protection from pathogen infection and modulation of the immune system via the gastrointestinal tract [11-13]. Lactobacillus reuteri alleviates 
ampicillin- or lipopolysaccharide-induced colitis and gut dysbiosis [14,15]. TNF- $\alpha$ expressioninhibiting Lactobacillus johnsonii significantly alleviates 2,4,6-trinitrobenzenesulfonic acidor immobilization stress-generated gut inflammation and disruption in mice $[15,16]$. IL-6 expression-inhibitory Lactobacillus reuteri NK33 alleviates immobilization stress-generated gut inflammation and dysbiosis in mice [17]. TNF- $\alpha$ expression-inhibitory Lactobacillus mисоsae NK41 alleviates Escherichia coli-generated gut inflammation and dysbiosis in mice [18]. IL-10 expression-inducing Lactobacilli alleviate high-fat diet-generated gut inflammation and microbiota alteration in mice [19]. However, TNF- $\alpha$ express-inducing probiotics potentiate the immune response in mice [20]. These results suggest that probiotics are able to mitigate hyperresponsive and hyporesponsive immune responses. However, how probiotics can homeostatically regulate the immune responses remains unclear.

Therefore, we selected a probiotic Lactobacillus rhamnosus HDB1258, which could induce TNF- $\alpha$ and IL-10 expression in macrophages, from bacterial strains isolated from the feces of breastfeeding infants and examined its effects on the innate and adaptive immune responses in the spleen and colon of mice with or without LPS-induced systemic inflammation.

\section{Results}

\section{Effect of HDB1258 on the expression of TNF- $\alpha$ and IL-10 in vitro}

To determine whether HDB1258, which was isolated as a TNF- $\alpha$ expression-inducing probiotic in macrophage from the feces of breastfeeding infants, could modulate the homeostatic immune response, we first examined its effect on the expression of TNF- $\alpha$ and IL-10 in macrophages stimulated with or without LPS (Figure 1). HDB1258 significantly induced the expression of 
TNF- $\alpha$, IL-6, and IL-10 in macrophage cells. HDB1258 also increased the expression ratio of TNF- $\alpha$ to IL-10. However, HDB1258 suppressed the expression of TNF- $\alpha$ and IL-6 in LPSactivated macrophages and did not affect the expression of IL-10. Furthermore, it increased the ratio of IL-10 to TNF- $\alpha$ expression in LPS-stimulated macrophages. HDB1258 was identified as Lactobacillus rhamnosus on the basis on the results of Gram staining, 16S rDNA sequencing (GenBank accession number MW193326), and API 50 CHL kit.

\section{HDB1258 potentiated the immune response including the innate and adaptive immune} systems in mice

Next, we examined the effect of HDB1258 and Saccharomyces cerevisiae (SC) $\beta$-glucan on the cytotoxicity of NK cell and phagocytosis of macrophages in mice (Figure 2). HDB1258 significantly increased splenic NK cell cytotoxicity against YAC-1 tumor cells and peritoneal macrophage phagocytic activity against Candida albicans. Furthermore, oral gavage of HDB1258, but not SC $\beta$-glucan, increased the secretion of $\operatorname{IgA}$ into the feces. We also examined the effect of HDB1258 on the $\mathrm{CD} 4^{+} \mathrm{IFN} \gamma^{+}$(Th1) and $\mathrm{CD}^{+} \mathrm{CD} 25^{+} \mathrm{Foxp}^{+}$(Treg) cell differentiation and their transcription factor expression in the spleen of mice. Oral gavage of HDB1258 or SC $\beta$-glucan did affect Th1 and Treg cell differentiation and their transcription factor expression. It also increased significantly increased TNF- $\alpha$ expression. However, it did not significantly affect the expression of IL-10 in the spleen, assessed by qPCR. As a result, oral gavage of HDB1258, but not SC $\beta$-glucan, increased the ratio of TNF- $\alpha$ to IL-10 expression in the spleen.

Oral gavage of HDB1258 or SC $\beta$-glucan induced TNF- $\alpha$, IL-1 $\beta$, IL-6, and IL-10 expression in the in the colon (Figure 3). It increased myeloperoxidase activity and NF-kB ${ }^{+} / \mathrm{CD}_{11 \mathrm{c}^{+} \text {cell }}$ population. In particular, it increased the ratio of TNF- $\alpha$ to IL-10 expression in the colon. 


\section{Effect of HDB1258 on gut microbiota composition in mice}

128

We examined whether the immunopotentiating effects of HDB1258 and SC $\beta$-glucan were associated with the composition of gut microbiota in mice (Figure 4). Oral gavage of HDB1258 also modified the composition of gut microbiota in mice: it shifted $\beta$-diversity (principal coordinate analysis [PCoA]) while the $\alpha$-diversity (operational taxonomic unit [OUT] richness) was not affected. HDB1258 treatment also increased the Cyanobacteria and Tenericutes populations and reduced the Firmicutes and Deferribacteres populations at the phylum level. It also increased the Bacteroidaceae and FR888536_f (belonging to cyanobacteria) populations at the family level, PAC000664_g (belonging to Firmicutes), Paraprevotella, Muribaculaceae_uc populations at the genus level, and AB606242_s (belonging to Fimicutes), PAC001072_s (belonging to Bacteroidetes), and FJ880724_s (belonging to Bacteroidetes) population at the species level and reduced the Heliobacteriaceae, Deferribacteriaceae, and Coribacteriaceae populations at the family level, Prevotellaceae_uc, LLKB_g (belonging to Firmicutes), and Eubacterium_g6 populations at the genus level, and EU505186_s (belonging to Bacteroidetes) and AB626939_s (belonging to Firmicutes) populations at the species level. To determine whether gut microbiota are related to the immunopotentiating effects of HDB1258, we analyzed the correlation between the ratio of TNF- $\alpha$ to IL-10 expression and gut microbiota in mice treated with and without HDB1258. Mycoplasmataceae $(\mathrm{R}=0.371$, $\mathrm{p}=0.052), \quad$ PAC001066_g $\quad(\mathrm{R}=0.530, \quad \mathrm{p}=0.069), \quad$ PAC001765_g $\quad(\mathrm{R}=0.585, \quad \mathrm{p}=0.002)$, Mycoplasma_g10 ( $\mathrm{R}=0.364, \mathrm{p}=0.055)$, PAC001072_s $(\mathrm{R}=0.055, \mathrm{p}=0.002)$, PAC001076_s $(\mathrm{R}=0.604, \mathrm{p}<0.001), \mathrm{PAC} 002476 \_\mathrm{s}(\mathrm{R}=0.382, \mathrm{p}=0.045), \mathrm{PAC} 002451 \_\mathrm{s}(\mathrm{R}=0.654, \mathrm{p}<0.001)$, PAC000198_g_uc $(\mathrm{R}=0.402, \mathrm{p}=0.034)$, and PAC002480_s $(\mathrm{R}=0.500, \mathrm{p}=0.007)$ populations showed a positive correlation with the ratio of TNF- $\alpha$ to IL-10 expression in the colon. 
Frisingicoccus $(\mathrm{R}=-0.472, \mathrm{p}=0.018)$, PAC002462_g $(\mathrm{R}=0 .-0.392, \mathrm{p}=0.049)$, PAC001236_g $(\mathrm{R}=-0.360, \mathrm{p}=0.051)$, PAC001070_s group $(\mathrm{R}=-0.355, \mathrm{p}=0.064)$ populations showed a negative correlation with the ratio of TNF- $\alpha$ to IL-10 expression in the colon. PAC001765_g $(\mathrm{R}=0.364, \mathrm{p}=0.057), \mathrm{PAC} 001127 \_\mathrm{g}(\mathrm{R}=0.342, \mathrm{p}=0.075), \mathrm{PAC} 001072 \_\mathrm{s}(\mathrm{R}=0.498, \mathrm{p}=0.007)$, PAC001084_s $(\mathrm{R}=0.322, \mathrm{p}=0.095)$, PAC001076_s $\quad(\mathrm{R}=0.385, \mathrm{p}=0.043)$, PAC002451_s $(\mathrm{R}=0.454, \mathrm{p}=0.015)$, PAC001081_s group $(\mathrm{R}=0.380, \mathrm{p}=0.046)$, PAC001114_s $(\mathrm{R}=0.453$, $\mathrm{p}=0.015), \quad$ PAC001095_s $\quad(\mathrm{R}=0.409, \mathrm{p}=0.031)$, PAC001113_s $\quad(\mathrm{R}=0.448, \mathrm{p}=0.017)$, and PAC002480_s $(\mathrm{R}=0.383, \mathrm{p}=0.044)$ populations showed a positive correlation with the ratio of TNF- $\alpha$ to IL-10 expression in the spleen. Frisingicoccus $(R=-0.368, p=0.054)$, PAC000197_g $(\mathrm{R}=-0.303, \mathrm{p}=0.118)$, PAC001236_g $(\mathrm{R}=-0.327, \mathrm{p}=0.090)$ populations showed a negative correlation with the ratio of TNF- $\alpha$ to IL-10 expression in the spleen.

\section{HDB1258 alleviated LPS-induced inflammation in mice}

Next, we examined the effect of HDB1258 on the cytotoxicity of NK cell and phagocytosis of macrophages in LPS-stimulated mice (Figure 4). Intraperitoneal injection of LPS significantly increased NK cell cytotoxicity against YAC-1 tumor cells and peritoneal macrophage phagocytic activity against Candida albicans. However, HDB1258 significantly suppressed LPS-induced NK cell cytotoxicity and macrophage phagocytosis. Furthermore, HDB1258 treatment suppressed the LPS-induced PGE2 level. Next, we examined the effect of HDB1258 on LPS-induced systemic inflammation in mice (Figure 5). Intraperitoneal injection of LPS significantly suppressed the $\mathrm{CD} 4^{+} \mathrm{CD} 25^{+} \mathrm{Foxp} 3^{+}$(Treg) cell population in the spleen, while the CD4+IFN $\gamma+($ Th1) cell population was not affected. Nevertheless, LPS treatment suppressed the ratio of $\mathrm{CD} 4^{+} \mathrm{CD} 25^{+} \mathrm{Foxp}^{+}$to $\mathrm{CD} 4+\mathrm{IFN} \gamma+$ cell population. Oral gavage of HDB1258 did not significantly affect the Th1 and Treg cell populations. However, HDB1258 treatment 
increased the LPS-suppressed ratio of Treg to Th1 cell population. LPS treatment increased the expression of Th1 transcription factor T-bet in the spleen while the expression of Treg cell transcription factor Foxp3 was weakly, but not significantly, suppressed. As a result, its treatment suppressed the ratio of Foxp3 to T-bet expression. Oral gavage of HDB1258 significantly reduced LPS-induced T-bet expression, while the Foxp3 expression was not affected. As a result, HDB1258 treatment increased the LPS-suppressed ratio of Treg to Th1 cell population. LPS treatment increased the TNF- $\alpha$ expression, while IL-10 expression decreased. Moreover, its treatment suppressed the ratio of IL-10 to TNF- $\alpha$ expression. Oral gavage of HDB1258 significantly suppressed LPS-induced TNF- $\alpha$ expression and induced LPS-suppressed IL-10 expression. As a result, HDB1258 treatment increased the LPSsuppressed ratio of IL-10 to TNF- $\alpha$ expression.

Furthermore, we examined the effect of HDB1258 on the colitis in mice with LPS-induced systemic inflammation (Figure 6). Intraperitoneal injection of LPS induced colitis: it induced colon shortening, IL-1 $\beta$, IL-6, and TNF- $\alpha$ expression and suppressed IL-10 expression in the colon. In particular, LPS treatment increased the TNF- $\alpha$ to IL-10 expression ratio and NF$\mathrm{kB}^{+} \mathrm{CD} 11 \mathrm{c}^{+}$cell population in the colon. However, oral gavage of HDB1258 significantly inhibited LPS-induced colon shortening and myeloperoxidase activity and $\mathrm{NF}-\mathrm{KB}^{+} / \mathrm{CD} 11 \mathrm{c}^{+}$ cell population. Furthermore, its treatment increased the ratio of IL-10 to TNF- $\alpha$ expression in the colon.

\section{HDB1258 partially modified LPS-disturbed gut microbiota composition in mice}

Next, we examined whether the anti-inflammatory effects of HDB1258 were associated with the gut microbiota composition in mice (Figure 7). Exposure to LPS also caused gut microbiota alteration in mice: it shifted $\beta$-diversity (PCoA) while the $\alpha$-diversity (OTU richness) was not 
affected. Furthermore, it increased cyanobacteria population and reduced the Tenericutes, Verrucomicrobia, and Deferribacteres populations. Oral gavage of HDB1258 changed LPSshifted $\beta$-diversity in the gut microbiota, while the $\alpha$-diversity was weakly, but not significantly, affected. HDB1258 treatment also increased LPS-suppressed Tenericutes, Verrucomicrobia, and Deferribacteres populations at the phylum level, Lachnospiraceae, Rikenellaceae, Helicobacteriaceae, Akkermansiaceae, Odoribacteriaceae, and Deferribacteraceae populations at the family level, KE159538_g (belonging to Firmicutes), PAC000664_g (belonging to Bacteroidetes), and Muribaculum populations at the genus level, and PAC001696_s (Firmicutes), PAC001120_s (belonging to Firmicutes), and PAC001077_s (belonging to Bacteroidetes) populations at the species level and reduced LPS-induced Erysipelotrichaceae population at the family level, Ruminococcus population at the genus level, and EU622763_s group (belonging to Bacteroidetes) population at the species level. To determine whether gut microbiota are related to the anti-inflammatory effect of HDB1258, we analyzed the correlation between the ratio of IL-10 to TNF- $\alpha$ expression and gut microbiota in mice with LPS-induced systemic inflammation. Rikenellaceae $(\mathrm{R}=0.507, \mathrm{p}=0.059)$, Lactobacillus $(\mathrm{R}=0.462, \mathrm{p}=0.014)$, Eubacterium_g23 $(\mathrm{R}=0.495, \quad \mathrm{p}=0.007), \quad$ PAC001070_s group $(\mathrm{R}=0.418, \quad \mathrm{p}=0.027)$, Lactobacillus murinus group $(\mathrm{R}=0.449, \mathrm{p}=0.017)$, Lactobacillus reuteri group $(\mathrm{R}=0.412$, $\mathrm{p}=0.029), \quad$ PAC001982_s $\quad(\mathrm{R}=0.434, \quad \mathrm{p}=0.021), \quad$ PAC000661_g_uc $\quad(\mathrm{R}=0.632, \quad \mathrm{p}<0.001)$ populations showed a positive correlation with the ratio of IL-10 to TNF- $\alpha$ expression in the colon. Erysipelotrichaceae $(\mathrm{R}=-0.517, \mathrm{p}=0.005)$, Sutterellaceae $(\mathrm{R}=-0.478, \mathrm{p}=0.010)$, Prevotellaceae_uc $(\mathrm{R}=-0.389, \mathrm{p}=0.041)$, PAC001066_g $(\mathrm{R}=-0.457, \mathrm{p}=0.015)$, PAC001072_s $(\mathrm{R}=-0.362, \mathrm{p}=0.059)$, PAC001066_s $(\mathrm{R}=-0.475, \mathrm{p}=0.011)$, PAC002478_s $(\mathrm{R}=-0.488$, $\mathrm{p}=0.009)$, PAC001756_s $(\mathrm{R}=-0.614, \mathrm{p}<0.001)$ populations showed a negative correlation with the ratio of IL-10 to TNF- $\alpha$ expression in the colon. Rikenellaceae $(R=0.434, p=0.021)$, 
Odoribacteraceae $(\mathrm{R}=0.406, \mathrm{p}=0.032)$, PAC000661_g $(\mathrm{R}=0.394, \mathrm{p}=0.038)$, Allobaculum $(\mathrm{R}=0.561, \mathrm{p}=0.002)$, Faecalibaculum $(\mathrm{R}=0.556, \mathrm{p}=0.002)$, Bacteroides acidifaciens group $(\mathrm{R}=0.412, \mathrm{p}=0.029)$, PAC001081_s group $(\mathrm{R}=0.420, \mathrm{p}=0.026)$, and FJ880578_s $(\mathrm{R}=0.537$, $\mathrm{p}=0.003$ ) populations showed a positive correlation with the ratio of IL-10 to TNF- $\alpha$ expression in the spleen. Erysipelotrichaceae $(R=-0.510, p=0.006)$, Sutterellaceae $(R=-0.510, p=0.006)$, Bifidobacteriaceae $(\mathrm{R}=-0.489, \mathrm{p}=0.008)$, Muribaculum $(\mathrm{R}=-0.410, \mathrm{p}=0.031)$, PAC001127_g $(\mathrm{R}=0.458, \mathrm{p}=0.014), \mathrm{PAC} 001084 \_\mathrm{s}(\mathrm{R}=-0.388, \mathrm{p}=0.042)$, and PAC001756_s $(\mathrm{R}=-0.531$, $\mathrm{p}=0.004)$ populations showed a negative correlation with the ratio of IL-10 to TNF- $\alpha$ expression in the spleen.

\section{Discussion}

The immune system consists of innate and adaptive immune systems that cooperatively protect the body from pathogenic microbes and toxins $[10,21]$. The attack of pathogenic microbes and toxins activates innate immune cells such as macrophages, dendritic cells, and NK cells, which secrete interferon (IFN)- $\gamma$, TNF- $\alpha$, IL-1 $\beta$, IL-6, and IL-10 [4,22]. These cytokines stimulate adaptive immune cells such as T cells, resulting in the differentiation of naïve T cells into Th1, Th2, Th17, and Treg cells [4,28,29]. The immunosuppression of host immune systems by stressors such as anticancer therapy cannot defend against pathogens and tumor progression. The hyperimmune responsiveness of host immune systems by pathogens, toxins, and allergens such as LPS excessively causes hypersensitivity including chronic inflammation through the activation of antigen-presenting cells and Th1/Treg cells $[8,23]$. A wide imbalance in innate and adaptive immune systems perturbs gut microbiota, which can affect host systemic immune system through the regulation of the gut immune system $[1,3,24]$. Therefore, maintaining a 
delicate balance in the immune system by protecting against infection by pathogens and toxins is important for the body's health.

In the present study, we found that oral administration of HDB1258, a novel probiotic isolated from healthy infant feces, significantly induced NK cell cytotoxicity against YAC-1 tumor cells, TNF- $\alpha$ to IL-10 expression ratio in the spleen, and TNF- $\alpha$, IL- $1 \beta$, and IL- 6 expression in the colon, and peritoneal macrophage phagocytosis against Candida albicans. Furthermore, HDB1258 increased the secretion of IgA into the feces, which serves as the first line of defense in protecting the gastrointestinal tract from pathogens and their toxins $[25,26]$. However, it did not affect the differentiation of Th1 and Treg cells and expression of their transcription factors T-bet and Foxp3. These results suggest that HDB1258 may enhance the immune response by activating innate immunity including macrophage phagocytosis and NK cell cytotoxicity, not adaptive immunity, in a healthy host.

The intraperitoneal injection of LPS caused systemic inflammation: it induced the phagocytosis of peritoneal macrophages against Candida albicans, while the ratios of Treg to Th1 cell differentiation and Foxp3 to T-bet expression and IL-10 to TNF- $\alpha$ expression in the spleen and colon were suppressed. However, oral administration of HDB1258 increased the differentiation of Treg cells, not Th1 cells, while macrophage phagocytosis decreased. Furthermore, HDB1258 treatment significantly suppressed T-bet and TNF- $\alpha$ expression and induced the expression of IL-10 in the spleen, resulting in an increase in the ratios of Foxp3 to T-bet and IL-10 to TNF- $\alpha$ expression. Oral administration of HD1258 also suppressed LPS-induced colon shortening, myeloperoxidase activity, TNF- $\alpha$, IL-1 $\beta$, and IL-6 expression in the colon, while IL-10 expression increased. Furthermore, it increased the LPS-suppressed ratio of IL-10 to TNF- $\alpha$ expression. Villena et al. reported that Lactobacillus rhamnosus suppressed the immune response by regulating the expression of IL-10, an anti-inflammatory cytokine [27]. 
270 Nigar et al. reported that Lactobacillus rhamnosus potentiated the immune response by 271 inducing the expression of IL-6 [28]. These results suggest that HDB1258 can suppress systemic inflammation including colitis by increasing the expression ratio of anti-inflammatory cytokines such as IL-10 to proinflammatory cytokines such as TNF- $\alpha$.

274 In addition, Zhang et al. reported that Lactobacillus rhamnosus GG suppressed allergic airway inflammation in mice by inducing the Treg cell population, which was closely associated with gut microbiota composition [29]. Wang et al. reported that Lactobacillus rhamnosus GG enhanced TNF- $\alpha$, IL-6, and IL-10 expression in gnotobiotic pigs vaccinated with an oral attenuated human rotavirus vaccine [30]. They suggested that Lactobacillus rhamnosus GG may regulate the homeostatic immune response by the modulation of gut microbiota. In the present study, we found that Lactobacillus rhamnosus enhanced the immune response in the healthy host by activating innate immune cells and suppressed the inflammatory response in the host with LPS-induced systemic inflammation by regulating innate and adaptive immune cells through the ratio of IL-10 to TNF- $\alpha$ expression. Moreover, oral administration of HDB1258 modified gut microbiota in mice with and without systemic inflammation. HDB1258 treatment also increased the Cyanobacteria and PAC000664_g (belonging to Bacteroidetes) populations and reduced Deferribacteres and EU622763_s group (belonging to Bacteroidetes) populations in mice with or without LPS-induced systemic inflammation. In particular, PAC001066_g and PAC001072_s populations showed a negative correlation with without LPS-induced systemic inflammation. PAC001127_g, and PAC001084_s, and PAC001756_s populations showed a negative correlation with the ratio of IL-10 to TNF- $\alpha$ expression in the spleen of mice with or without LPS-induced systemic inflammation. These 
results suggest that HDB1258 may regulate the immune system including gut immune response by modulating the microbiota composition.

296

297

\section{Conclusions}

298

299

300

HDB1258 may enhance the immune response by activating innate immunity including to macrophage phagocytosis and NK cell cytotoxicity, not the adaptive immunity, in the healthy host. HDB1258 can suppress systemic inflammation by increasing the expression ratio of antiby the modulation of gut microbiota and IL-10 to TNF- $\alpha$ expression ratio in the immune cells.

306

\section{Materials and Methods}

\section{Materials}

310

311 Sodium thioglycolate, 4',6-diamidino-2-phenylindole, dilactate (DAPI), and RPMI 1640 were purchased from Sigma (St. Louis, MO). Enzyme-linked immunosorbent assay (ELISA) kits for IL-1 $\beta$, IL-6, IL-10, and TNF- $\alpha$ were purchased from eBioscience (San Diego, CA). Antibodies were purchased from Cell Signaling Technology (Beverly, MA). CD4 T and NK cell isolation kits were purchased from Miltenyi Biotec (Teterow, Germany). A Vybrant CFDA SE Cell was purchased from Qiagen (Hiden, Germany). 
Culture of Lactobacillus rhamnosus HDB1258

Lactobacillus rhamnosus HDB1258 (named SKB1258 in the previous report) was inoculated into lava-seawater LAB media containing $8 \%$ glucose, $2 \%$ yeast extract, $0.5 \%$ soy peptone, $0.5 \%$ sodium acetate, $0.1 \%$ Tween $80,0.01 \% \mathrm{MgSO}_{4}, 0.005 \% \mathrm{MnSO}_{4}, 0.2 \%$ potassium diphosphate, and $0.2 \%$ ammonium sulfate in $30 \%(\mathrm{v} / \mathrm{v})$ lava-seawater $(\mathrm{pH} 6.5)$, incubated at $37^{\circ} \mathrm{Cfor} 20 \mathrm{~h}$, and centrifuged (5,000 g, $\left.30 \mathrm{~min}\right)$ [31]. The resulting precipitate was mixed with hydroxypropyl methylcellulose and trehalose and freeze-dried. For the in vitro and in vivo experiments, it was suspended in saline.

\section{Animals}

C57BL/6 mice (male, 5 weeks old, $19 \sim 21 \mathrm{~g}$ ) were supplied from Orient Bio (Seongnam-shi, Korea) and acclimatized for 7 days before the usage of experiments. All animals were maintained in the plastic cage with the $5 \mathrm{~cm}$-raised wire floor under standard conditions according to the NIH and University Guide for Laboratory Animal Care and Usage.

\section{Isolation and culture of macrophages}

Macrophages, which were isolated from the peritoneal cavity of mice intraperitoneally injected with sodium thioglycolate according to the method of Jang et al. [17], were suspended in RPMI 1640 containing $10 \%$ fetal bovine serum and $1 \%$ antibiotics (RFA), seeded in 6-well plate, incubated at $37^{\circ} \mathrm{C}$ for a day, and washed with RFA, as previously reported [14]. For the assay 
341 of IL-10 and TNF- $\alpha$ expression, macrophages were treated with LPS $(80 \mathrm{ng} / \mathrm{mL})$ in the presence or absence of HDB1258 $\left(1 \times 10^{5} \mathrm{CFU} / \mathrm{mL}\right)$ for $20 \mathrm{~h}$ [17].

Treatment with HDB1258, a probiotic, in mice with or without LPS-induced systemic inflammation

To examine the immunomodulating effect of HDB1258, it was orally gavaged in mice with or without LPS-induced systemic inflammation. Normal control mice were orally gavaged with vehicle (saline) instead of HDB1258. Each group consisted of 7 mice. First, HDB1258 (LL, $1 \times 10^{8} \mathrm{CFU} / \mathrm{mouse} /$ day; $\mathrm{LH}, 1 \times 10^{9} \mathrm{CFU} / \mathrm{mouse} /$ day $)$ or SC $\beta$-glucan $(50 \mathrm{mg} / \mathrm{kg} / \mathrm{day})$ was orally gavaged in control mice once a day for 14 days. Second, LPS $(10 \mu \mathrm{g} / \mathrm{mL}$, dissolved in $0.1 \mathrm{~mL}$ of saline) was intraperitoneally injected in mice once a day for 10 days according to the method of Jang et al. [15] and HDB1258 (LL, $1 \times 10^{8} \mathrm{CFU} / \mathrm{mouse} /$ day; LH, $1 \times 10^{9} \mathrm{CFU} / \mathrm{mouse} /$ day) was orally gavaged once a day for 14 days from next day after the final treatment with LPS. Mice were sacrificed $20 \mathrm{~h}$ after the final treatment with test agents by $\mathrm{CO}_{2}$ inhalation.

Flow cytometric analysis of Th1 and Treg cells in the spleen

For the flow cytometric analysis of Th1 and Treg cells in the spleen, spleens were removed from mice, crushed, lysed with Tris-buffered ammonium chloride, suspended in RPMI 1640 medium, and then filtered. The CD4 T cells were isolated from the filtrates using a Pan T cell Isolation Kit II [32]. Isolated $\mathrm{T}$ cells were fixed and stained with anti-IFN $\gamma$ or anti-Foxp3 antibodies and then analyzed by a flow cytometer. 
For the cytotoxic activity assay of splenic natural killer (NK) cells, NK cells were isolated from splenocytes prepared from the spleen of mice by using a NK cell isolation kit, as described previously [23]. The tumoricidal activity of the NK cells was evaluated by measuring the cytotoxicity against YAC-1 cells labeled with a Vybrant CFDA SE Cell Tracer kit according to the manufacturer's protocol. NK cells $\left(5 \times 10^{5}\right.$ per well) in the 96 -well microplates were cultured with YAC-1 cells $\left(5 \times 10^{5}\right.$ per well) for $24 \mathrm{~h}$. The cells were washed and stained with propodium iodide and analyzed by a flow cytometer, as reported previously [33].

\section{Phagocytosis assay of peritoneal macrophages}

Peritoneal macrophages were prepared as described previously [15]. Macrophage cells $\left(1 \times 10^{6}\right.$ cell/well) was incubated with Candida albicans $\left(1 \times 10^{4}\right.$ CFU/well, purchased from Korean Culture Center of Microorganisms (Seoul, Korea) in the 24-well microplates with complete RPMI 1640 medium and cultured for $24 \mathrm{~h}$. The cultured supernatant $(0.2 \mathrm{~mL})$ was inoculated in Sabouraud dextrose agar for $24 \mathrm{~h}$ at $30^{\circ} \mathrm{C}$. The phagocytic activity (\%) was indicated as [1(the number of C. albicans colonies grown in SDA per the number of Candida albicans initially incubated with macrophages)] x 100 .

\section{Assay of myeloperoxidase activity}

Myeloperoxidase activity was assayed according to the method of Jang et al. [15]. Colons were homogenized with cold RIPA lysis buffer and centrifuged at $10,000 \mathrm{~g}$ for $10 \mathrm{~min}$. The supernatant was used as a crude enzyme solution. An aliquot $(0.05 \mathrm{~mL})$ of the supernatant was added in the reaction mixture $(0.95 \mathrm{~mL})$ containing $0.03 \%$ hydrogen peroxide and $1.6 \mathrm{mM}$ tetramethylbenzidine. The absorbance at $650 \mathrm{~nm}$ time was monitored over $5 \mathrm{~min}$. Activity was defined as the quantity degrading $1 \mu \mathrm{mol} / \mathrm{mL}$ of peroxide. 


\section{Quantitative real time-polymerase chain reaction (qPCR)}

390

Genomic RNA $(2 \mu \mathrm{g})$ was isolated from the spleen of mice. The qPCR for TNF- $\alpha$, IL-10, Tbet, Foxp3, and $\beta$-actin was performed utilizing Takara thermal cycler, which used SYBER premix agents: activation of DNA polymerase at $95^{\circ} \mathrm{C}$ for 5 min and 45 cycles of amplification at $95^{\circ} \mathrm{C}$ for $10 \mathrm{~s}$ and at $60^{\circ} \mathrm{C}$ for $30 \mathrm{~s}$ [34]. The normalized expression of the assayed genes (TNF- $\alpha$, IL-10, Foxp3, T-bet, and $\beta$-actin: their primers are described in Table S1), with respect to $\beta$-actin, was computed for all samples by using the Microsoft Excel data spreadsheet.

\section{ELISA}

Colon tissues were lysed with ice-cold lysis RIPA buffer containing $50 \mathrm{mM}$ Tris- $\mathrm{HCl}$ (pH 8.0), $150 \mathrm{mM}$ sodium chloride, $1.0 \%$ Igepal CA-63, $0.5 \%$ sodium deoxycholate, $0.1 \%$ sodium dodecyl sulfate (SDS), $1 \%$ phosphatase inhibitor cocktail and $1 \%$ protease inhibitor cocktail and were centrifuged $\left(10,000 \mathrm{~g}, 4^{\circ} \mathbf{C}\right.$, and $\left.10 \mathrm{~min}\right)$ [17]. For the assay of cytokines, colon homogenate supernatants were transferred in 96-well plate and assayed using ELISA Kits.

\section{Immunofluorescence assay}

Immunofluorescence assay was performed according to the method of Kim et al. [18]. Briefly, the colon section was washed with phosphate-buffered saline, incubated with antibodies for TNF- $\alpha$ (1:200) antibody overnight, and treated with the secondary antibody for $2 \mathrm{~h}$. A secondary antibody conjugated with Alexa Fluor 488 (1:200) was incubated to visualize. Nuclei were stained with DAPI.

\section{S rRNA gene pyrosequencing}


412 The bacterial genomic DNA was extracted for the fresh feces of mice using a QIAamp DNA

413 stool mini kit according to Kim et al. [18]. The genomic DNA was amplified using barcoded

414 primers targeted the bacterial 16S rRNA V4 region gene. Each amplicon was sequenced using 415 Illumina iSeq 100 (San Diego, CA). Functional genes was predicted using the phylogenetic 416 investigation of communities by reconstruction of unobserved states (PICRUSt) [18,35]. Linear discriminant analysis (LDA) and cladograms were pictured using the LDA effect size (LefSe) on Galaxy platform (https://huttenhower.sph.harvard.edu/galaxy/) [36].

\section{Statistical analysis}

All data are indicated as the means \pm standard deviation (SD) and conducted GraphPad Prism

8 (GraphPad Software, Inc., San Diego, CA, USA). The significance was analyzed by Kruskal-Wallis test with Dunn's post-hoc test for non-parametric analysis $(p<0.05)$.

\section{Supplementary information}

Additional file 1 is available. It contains the following Tables and Figures. Table S1. Primer sequences used in the present study. Table S2. Effect of HDB1258 on the gut microbiota composition at the family level in mice. Table S3. Effect of HDB1258 on the gut microbiota composition at the genus level in mice. Table S4. Effect of HDB1258 on the gut microbiota composition at the species level in mice. Table S5. Effect of HDB1258 on the gut microbiota composition at the family level in mice with LPS-induced systemic inflammation. Table S6. Effect of HDB1258 on the gut microbiota composition at the genus level in mice with LPSinduced systemic inflammation. Table S7. Effect of HDB1258 on the gut microbiota composition at the species level in mice with LPS-induced systemic inflammation. Figure S1. 
436 The correlation between gut microbiota (at the species level) and ratio of TNF- $\alpha$ to IL-10

437 expression in the healthy mice. Figure S2. The correlation between gut microbiota (at the 438 species level) and ratio of TNF- $\alpha$ to IL-10 expression in mice with LPS-induced systemic 439 inflammation.

440

441 Abbreviations

442 IFN: interferon; IL: interleukin; LPS: lipopolysaccharide; NK: natural killer; OUT:

443 operational taxonomic unit; PCoA: principal coordinate analysis; SC: Saccharomyces

444 cerevisiae; Th: helper T; TNF: tumor necrosis factor; Treg: regulatory T.

445

446 Declarations

447

448

Ethics approval and consent to participate

449

All animal experimental procedures were approved by the Institutional Animal Care and Use 450 Committee of the University (IACUC No. KUSASP-20018).

451

452

\section{Consent for publication}

453 Not applicable.

454

455 Availability of data and materials

456 Pyrosequencing reads were deposited in the short read archive of NCBI under accession 457 number PRJNA678595.

458

459 Competing interests 
The authors have declared no conflict of interest.

461

462

Funding

463

This research was funded by the Medical Research Program through the National Research

464 Foundation of Korea (NRF) funded by the Ministry of Science and ICT (NRF465 2017R1A5A2014768).

466

467

\section{Authors' contributions}

468

SKH, SL, and DHK: conceptualization and experiment design; SKH, YJS, DYL, KMK, SJY, and DSK; experiment and data analysis; SKH, YJS, DYL, KMK, SJY, DSK, and JWC: investigation; SKH, YJS, SL, and DHK: manuscript writing. All authors reviewed and agreed to the published version of the manuscript.

472

\section{Acknowledgements}

474 This research was funded by the Medical Research Program through the National Research 475 Foundation of Korea (NRF) funded by the Ministry of Science and ICT (NRF2017R1A5A2014768).

477

\section{Authors' information}

479 Sang-Kap Han, Yeon-Jeong Shin, Dong-Yeon Lee, and Dong-Hyun Kim.

Neurobiota Research Center, College of Pharmacy, Kyung Hee University, 26,

Kyungheedae-ro, Dongdaemun-gu, Seoul 02447, Korea

482

Kyung Min Kim, Seo-Jin Yang, Du Seong Kim, Ji-Whi Choi, and Seunghun Lee.

483 HYUNDAI Bioland Co., Ltd., Ansan 15407, Korea. 


\section{References}

486

1. Wu HJ, Wu E. The role of gut microbiota in immune homeostasis and autoimmunity. Gut Microbes. 2012; 3: 4-14.

2. Belkaid Y, Hand T. Role of the microbiota in immunity and inflammation. Cell. 2014; 157 : $121-141$.

3. Pickard JM, Zeng MY, Caruso R, Núñez G. Gut microbiota: role in pathogen colonization, immune responses and inflammatory disease. Immunol Rev. 2017; 279: 70-89.

4. Kany S, Vollrath JT, Relja B. Cytokines in inflammatory disease. Int J Mol Sci. 2019; 20: 6008.

5. Mendes V, Galvão I, Vieira AT. Mechanisms by which the gut microbiota influences cytokine production and modulates host inflammatory responses. J Interferon Cytokine Res 2019; 39: 393-409.

6. ChaplinDD. Overview of the Immune Response. J Allergy Clin Immunol. 2010; 125 (Suppl 2): $\mathrm{S} 3-23$.

7. Kaiko GE, Horvat JC, Beagley KW, Hansbro PM. Immunological decision-making: how does the immune system decide to mount a helper T-cell response? Immunology. 2008; 123 : $326-338$.

8. Gaudino SJ, Kumar P. Cross-talk between antigen presenting cells and T cells impacts intestinal homeostasis, bacterial Infections, and tumorigenesis. Front Immunol. 2019; 10:360.

9. Haapakoski R, Ebmeier KP, Alenius H, Kivimäkia M. Innate and adaptive immunity in the development of depression: An update on current knowledge and technological advances. Prog Neuropsychopharmacol Biol Psychiatry. 2016; 66: 63-72. 
10. Zheng D, Liwinski T, Elinav E. Interaction between microbiota and immunity in health and disease. Cell Res. 2020; 30: 492-506.

11. Hemarajata P, Versalovic J. Effects of probiotics on gut microbiota: mechanisms of intestinal immunomodulation and neuromodulation. Therap Adv Gastroenterol. 2013; 6: $39-51$.

12. Saulnier DM, Ringel Y, Heyman MB, Foster JA, Bercik P, Shulman RJ, Versalovic J, Verdu EF, Dinan TG, Hecht G, Guarner F. The intestinal microbiome, probiotics and prebiotics in neurogastroenterology. Gut Microbes 2013; 4: 17-27.

13. Kok CR, Hutkins R. Yogurt and other fermented foods as sources of health-promoting bacteria. Nutrition Rev. 2018; 76 (Supp 1): 4-15.

14. Jang HM, Lee HJ, Jang SE, Han MJ, Kim DH. Evidence for interplay among antibacterial-induced gut microbiota disturbance, neuro-inflammation, and anxiety in mice. Mucosal Immunol. 2018;11:1386-1397.

15. Jang HM, Lee KE, Lee HJ, Kim DH. Stress immobilization stress-induced Escherichia coli causes anxiety by inducing $\mathrm{NF}-\kappa \mathrm{B}$ activation through gut microbiota disturbance. Sci Rep. 2018; 8: 13897.

16. Jang SE, Lim SM, Jeong JJ, Jang HM, Lee HJ, Han MJ, Kim DH. Gastrointestinal inflammation by gut microbiota disturbance induces memory impairment in mice. Mucosal Immunol. 2018;11:369-379.

17. Jang HM, Lee KE, Kim DH. The preventive and curative effects of Lactobacillus reuteri NK33 and Bifidobacterium adolescentis NK98 on immobilization stress-induced anxiety/depression and colitis in mice. Nutrients. 2019; 11: 819. 
18. Kim JK, Lee KE, Lee SA, Jang HM, Kim DH. Interplay between human gut bacteria Escherichia coli and Lactobacillus mucosae in the occurrence of neuropsychiatric disorders in mice. Front Immunol. 2020; 11: 273.

19. Kim HI, Yun SW, Han MJ, Jang SE, Kim DH. IL-10 expression-inducing gut bacteria alleviate high-fat diet-induced obesity and hyperlipidemia in mice. J Microbiol Biotechnol 2020;30:599-603.

20. Jung IS, Jeon MG, Oh DS, Jung YJ, Kim HS, Bae D, Kim Y, Lee GE, Choi C, Hwang YP. Micronized, heat-treated Lactobacillus plantarum LM1004 alleviates cyclophosphamide-induced immune suppression. J Med Food. 2019;22:896-906.

21. Kim KM, Yang SJ, Kim DS, Lee CW, Kim HY, Lee S, Choi JW, Sohn J, Shin SS, Lee S. Probiotic properties and immune-stimulating effect of the Jeju lava seawater mineralcoated probiotics. LWT - Food Sci Technol. 2020; 126: 109299.

22. Lim SM, Jeong JJ, Choi HS, Chang HB, Kim DH. Mangiferin corrects the imbalance of Th17/Treg cells in mice with TNBS-induced colitis. Int Immunopharmacol. 2016;34:220228.

23. Jang SE, Joh EH, Lee HY, Ahn YT, Lee JH, Huh CH, Han MJ, Kim DH. Lactobacillus plantarum HY7712 ameliorates cyclophosphamide-induced immunosuppression in mice. J Microbiol Biotechnol. 2013;23:414-421.

24. Lim SM, Lee SY, Jeong JJ, Choi HS, Chang HB, Kim DH. DW2007 Ameliorates Colitis and Rheumatoid Arthritis in Mice by Correcting Th17/Treg Imbalance and Inhibiting NF«B Activation. Biomol Ther (Seoul). 2016;24:638-649.

25. Langille, M.G., Zaneveld, J., Caporaso, J.G., McDonald, D., Knights, D., Reyes, J.A. et al. (2013) Predictive functional profiling of microbial communities using 16S rRNA marker gene sequences. Nat. Biotechnol. 31, 814-821. 
26. Segata, N., Izard, J., Waldron, L., Gevers, D., Miropolsky, L., Garrett, W.S., et al. (2011) Metagenomic biomarker discovery and explanation. Genome Biol. 12, R60.

27. Iwasaki A, Medzhitov R. Control of adaptive immunity by the innate immune system. Nat Immunol. 2015;16:343-53.

28. Turner MD, Nedjai B, Hurst T, Pennington DJ. Cytokines and chemokines: At the crossroads of cell signalling and inflammatory disease. Biochim Biophys Acta. 2014;1843:2563-2582.

29. Furiati SC, Catarino JS, Silva MV, Silva RF, Estevam RB, Teodoro RB, Pereira SL, Ataide M, Rodrigues Jr V, Rodrigues DBR. Th1, Th17, and Treg responses are differently modulated by TNF- $\alpha$ inhibitors and methotrexate in psoriasis patients. Sci Rep. 2019;9:7526.

30. Lazar V, Ditu LM, Pircalabioru GG, Gheorghe I, Curutiu C, Holban AM, Picu A, Petcu L, Chifiriuc MC. Aspects of gut microbiota and immune system interactions in infectious diseases, immunopathology, and cancer. Front Immunol. 2018;9:1830.

31. Mantis NJ, Rol N, Corthésy B. Secretory IgA's complex roles in immunity and mucosal homeostasis in the gut. Mucosal Immunol. 2011; 4: 603-611.

32. Strugnell RA, Wijburg OLC. The role of secretory antibodies in infection immunity. Nat Rev Microbiol. 2010;8:656-67.

33. Villena J, Chiba E, Tomosada Y, Salva S, Marranzino G, Kitazawa H, Alvarez S. Orally administered Lactobacillus rhamnosus modulates the respiratory immune response triggered by the viral pathogen-associated molecular pattern poly(I:C). BMC Immunol. 2012; 13: 53 .

34. Nigar S, Yamamoto Y, Okajima T, Shigemori S, Sato T, Ogita T, Shimosato T. Synergistic oligodeoxynucleotide strongly promotes CpG-induced interleukin-6 
production. BMC Immunol. 2017; 18: 44.

579 35. Wang H, Gao K, Wen K, Allen IC, Li G, Zhang W, Kocher J, Yang X, Giri-Rachman E,

580 Li GH, Clark-Deener S, Yuan L. Lactobacillus rhamnosus GG modulates innate signaling

581 pathway and cytokine responses to rotavirus vaccine in intestinal mononuclear cells of

582 gnotobiotic pigs transplanted with human gut microbiota. BMC Microbiol. 2016;16:109.

583 36. Zhang J, Ma JY, Li QH, Su H, Sun X. Lactobacillus rhamnosus GG induced protective

584 effect on allergic airway inflammation is associated with gut microbiota. Cell Immunol.

$585 \quad 2018 ; 332: 77-84$.

586 
Figure 1. Effect of HDB1258 on the expression of proinflammatory cytokines in macrophages stimulated with or without LPS. (A) Effect on TNF- $\alpha$ (a), IL-6 (b), and IL-10 expression (c) and ratio of TNF- $\alpha$ to IL-10 expression (d) in macrophage cells. (B) Effect on TNF- $\alpha$ (a), IL-6 (b), and IL-10 expression (c) and ratio of TNF- $\alpha$ to IL-10 expression (d) in LPS-stimulated macrophage cells. Macrophage cells $\left(1 \times 10^{6} / \mathrm{mL}\right)$ isolated from peritoneal cavity were incubated with HDB1258 (LL, $1 \times 10^{4} \mathrm{CFU} / \mathrm{mL}$; LH, $1 \times 10^{5} \mathrm{CFU} / \mathrm{mL}$ ) in the absence or presence of LPS. Normal control group (CON) was treated with saline instead of LPS. Data values were described as mean $\pm \mathrm{SD}(\mathrm{n}=4) .{ }^{\#} p<0.05$ vs. CON. ${ }^{*} p<0.05$ vs. group treated with LPS alone.

598

Figure 2. Effect of HDB1258 and Saccharomyces cerevisiae (SC) $\beta$-glucan on splenic NK cell cytotoxicity, peritoneal macrophage phagocytosis, fecal IgA level, splenic Th1 and Treg cell differentiation, splenic T-bet, Foxp3, TNF- $\alpha$, and IL-10 expression in mice. (A) Effects on splenic NK cell cytotoxicity (a), peritoneal macrophage phagocytosis (b), and fecal IgA level (c). (B) Effects on the differentiation of Th1 (a) and Treg cells (b) and ratio of Th1 to Treg cells (c). Effects on the expression of T cell transcription factors T-bet (a) and Foxp3 (b) and ratio of T-bet to Foxp3 expression (c). Effects on the expression of TNF- $\alpha$ (a) and IL-10 (b) and ratio of TNF- $\alpha$ to IL-10 expression. HDB1258 (LL, $1 \times 10^{8} \mathrm{CFU} /$ mouse/day and LH, $1 \times 10^{9}$ $\mathrm{CFU} / \mathrm{mouse} /$ day) or SC $\beta$-glucan (SCG, $50 \mathrm{mg} / \mathrm{kg} /$ day) was orally gavaged daily for 14 days. 608 Normal control mice (CON) were treated with vehicle (saline) instead of test agents. Data 609 values were described as mean $\pm \mathrm{SD}(\mathrm{n}=6) .{ }^{*} p<0.05$ vs. $\mathrm{CON}$. 
611 Figure 3. Effect of HDB1258 and SC $\beta$-glucan on the TNF- $\alpha$ (a), IL-10 (b), IL-6 (c), and IL$6121 \beta$ expression (d), ratio of TNF- $\alpha$ to IL-10 expression (e), and NF- $\mathrm{KB}^{+} \mathrm{CD} 11 \mathrm{c}^{+}$cell population 613 (f) in the colon of mice. HDB1258 (LL, $1 \times 10^{8} \mathrm{CFU} /$ mouse/day and $\mathrm{LH}, 1 \times 10^{9} \mathrm{CFU} / \mathrm{mouse} /$ day) 614 or SC $\beta$-glucan (SCG, $50 \mathrm{mg} / \mathrm{kg} / \mathrm{day}$ ) was orally gavaged daily for 14 days. Normal control 615 mice $(\mathrm{CON})$ were treated with vehicle (saline) instead of test agents. Data values were 616 described as mean \pm SD $(n=6)$. Means with same letters are not significantly different $(p<$ $6170.05)$

618

619 Figure 4. Effect of HDB1258 and SC $\beta$-glucan on the gut microbiota composition in mice. (A) 620 Effects on $\alpha$-diversity (OUT richness). (B) Effects on $\beta$-diversity. (C) Effects on the gut 621 bacteria composition at the phylum level. (D) The correlation between gut microbiota (at the 622 family and genus levels) and ratio of TNF- $\alpha$ to IL-10 expression in the colon. (E) The correlation between gut microbiota (at the family and genus levels) and TNF- $\alpha$ to IL-10 expression ratio in the spleen. HDB1258 (LL, $1 \times 10^{8} \mathrm{CFU} /$ mouse/day and $\mathrm{LH}, 1 \times 10^{9}$ $\mathrm{CFU} / \mathrm{mouse} /$ day) or SC $\beta$-glucan (SCG, $50 \mathrm{mg} / \mathrm{kg} /$ day) was orally gavaged daily for 14 days. Normal control group (CON) was treated with saline instead of test agents. Data values were described as mean $\pm \operatorname{SD}(\mathrm{n}=6) .{ }^{*} p<0.05$ vs. CON.

628

Figure 5. Effect of HDB1258 on splenic NK cell cytotoxicity, peritoneal macrophage phagocytosis, blood PGE2 level, splenic Th1 and Treg cell differentiation, splenic T-bet, Foxp3, TNF- $\alpha$, and IL-10 expression in mice with LPS-induced systemic inflammation. (A) Effects on splenic NK cell cytotoxicity (a), peritoneal macrophage phagocytosis (b), and blood PGE2 level (c). (B) Effects on the differentiation of Th1 (a) and Treg cells (b) and ratio of Th1 to Treg cells (c). Effects on the expression of T cell transcription factors T-bet (a) and Foxp3 (b) 
and ratio of T-bet to Foxp3 expression (c). Effects on the expression of TNF- $\alpha$ (a) and IL-10

636

637

638

639

640

641

642

643

644

645

646

647

648

649

650

651

652

653

654

655

656

657

658

(b) and ratio of TNF- $\alpha$ to IL-10 expression. Mice was interaperitoneally injected with LPS (10 $\mu \mathrm{g} / \mathrm{kg} /$ day) for 10 days. HDB1258 (LPS, vehicle; LL, $1 \times 10^{8} \mathrm{CFU} / \mathrm{mouse} /$ day and LH, $1 \times 10^{9}$ CFU/mouse/day) was orally gavaged daily for 14 days from the final injection of LPS. Normal control mice $(\mathrm{CON})$ were treated with saline instead of LPS and test agents. Data values were described as mean $\pm \mathrm{SD}(\mathrm{n}=6) .{ }^{*} p<0.05$ vs. CON. ${ }^{*} p<0.05$ vs. group treated with LPS alone.

Figure 6. Effect of HDB1258 on the LPS-induced colitis in mice with LPS-induced systemic inflammation. on the colon length (a), myeloperoxidase (MPO) activity (b), IL-1 (c), IL-6 (d), TNF- $\alpha$ (e), and IL-10 expression (f), ratio of IL-10 to TNF- $\alpha$ expression (g), and NF$\kappa^{+} \mathrm{CD} 11 \mathrm{c}^{+}$cell population (h). Mice was intraperitoneally injected with LPS $(10 \mu \mathrm{g} / \mathrm{kg} / \mathrm{day})$ for 10 days. HDB1258 (LPS, vehicle; LL, $1 \times 10^{8} \mathrm{CFU} /$ mouse/day and LH, $1 \times 10^{9}$ CFU/mouse/day) was orally gavaged daily for 14 days from the final injection of LPS. Normal control mice (CON) were treated with saline instead of LPS and test agents. Data values were described as mean $\pm \mathrm{SD}(\mathrm{n}=6) .{ }^{\#} p<0.05$ vs. CON. ${ }^{*} p<0.05$ vs. group treated with LPS alone.

Figure 7. Effect of HDB1258 on the composition of gut microbiota in mice with LPSinduced systemic inflammation. (A) Effects on $\alpha$-diversity (OUT richness). (B) Effects on $\beta$ diversity. (C) Effects on the gut bacteria composition at the phylum level. (D) The correlation between gut microbiota (at the family and genus levels) and ratio of IL-10 to TNF- $\alpha$ expression in the colon. (E) The correlation between gut microbiota (at the family and genus levels) and ratio of IL-10 to TNF- $\alpha$ expression in the spleen. Mice was intraperitoneally injected with LPS (10 $\mu \mathrm{g} / \mathrm{kg} /$ day) for 10 days. HDB1258 (LPS, vehicle; LL, $1 \times 10^{8}$ 
$659 \mathrm{CFU} / \mathrm{mouse} /$ day and $\mathrm{LH}, 1 \times 10^{9} \mathrm{CFU} / \mathrm{mouse} /$ day) was orally gavaged daily for 14 days from 660 the final injection of LPS. Normal control mice (CON) were treated with vehicle (saline)

661 instead of LPS and test agents. Data values were described as mean \pm SD $(\mathrm{n}=6) .{ }^{\#} p<0.05$ 662 vs. CON. ${ }^{*} p<0.05$ vs. group treated with LPS alone. 
Figures

(A) (a)

(b)
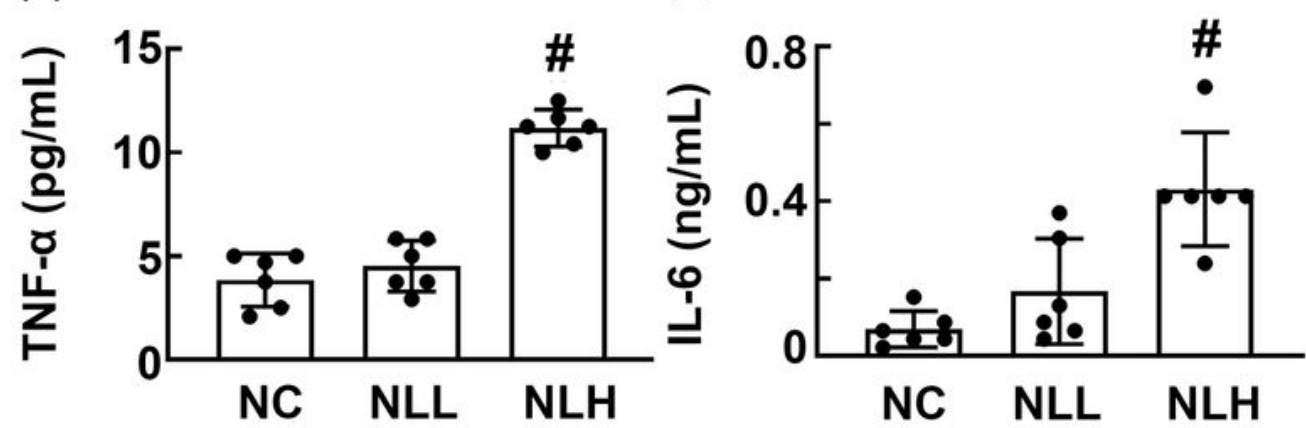

(c)

(d)
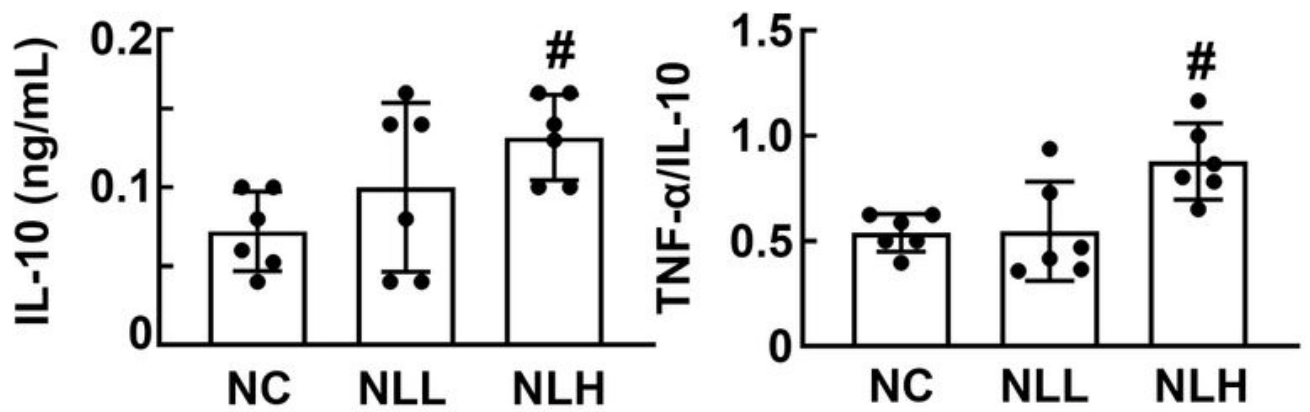

(B) (a)

(b)
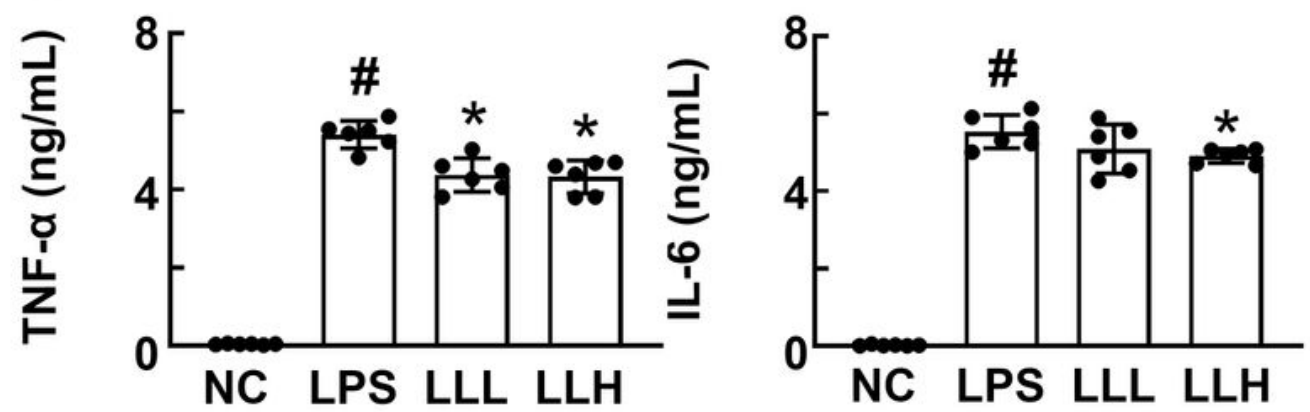

(c)

(d)
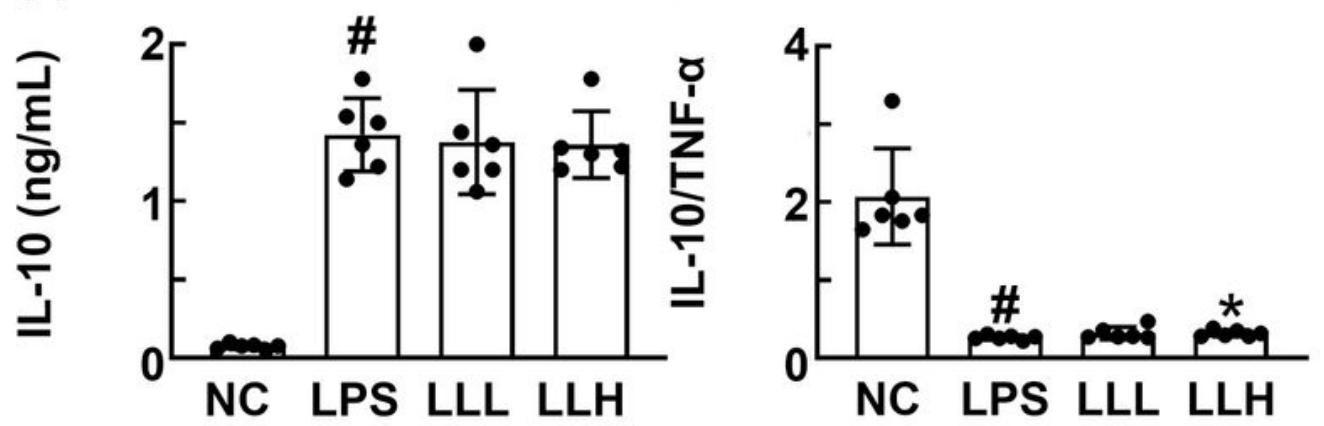

Figure 1

Effect of HDB1258 on the expression of proinflammatory cytokines in macrophages stimulated with or without LPS. (A) Effect on TNF-a (a), IL-6 (b), and IL-10 expression (c) and ratio of TNF-a to IL-10 expression (d) in macrophage cells. (B) Effect on TNF-a (a), IL-6 (b), and IL-10 expression (c) and ratio of 
TNF-a to IL-10 expression (d) in LPS-stimulated macrophage cells. Macrophage cells $(1 \times 106 / \mathrm{mL})$ isolated from peritoneal cavity were incubated with HDB1258 (LL, $1 \times 104 \mathrm{CFU} / \mathrm{mL} ; \mathrm{LH}, 1 \times 105 \mathrm{CFU} / \mathrm{mL}$ ) in the absence or presence of LPS. Normal control group (CON) was treated with saline instead of LPS. Data values were described as mean $\pm \operatorname{SD}(n=4)$. $\# p<0.05$ vs. CON. ${ }^{*} p<0.05$ vs. group treated with LPS alone.

(A)

(a)

(b)

(c)
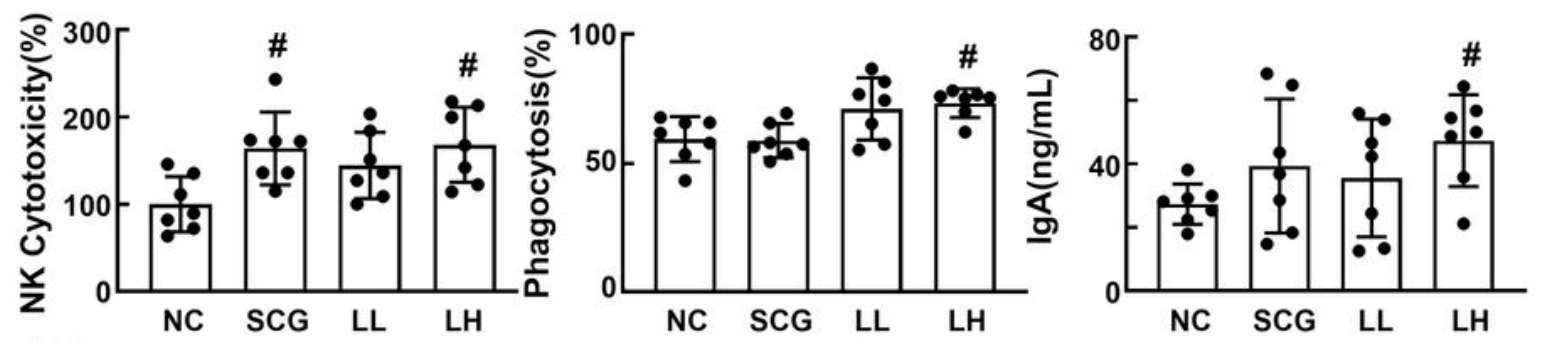

(B)

(a)

(b)

(c)
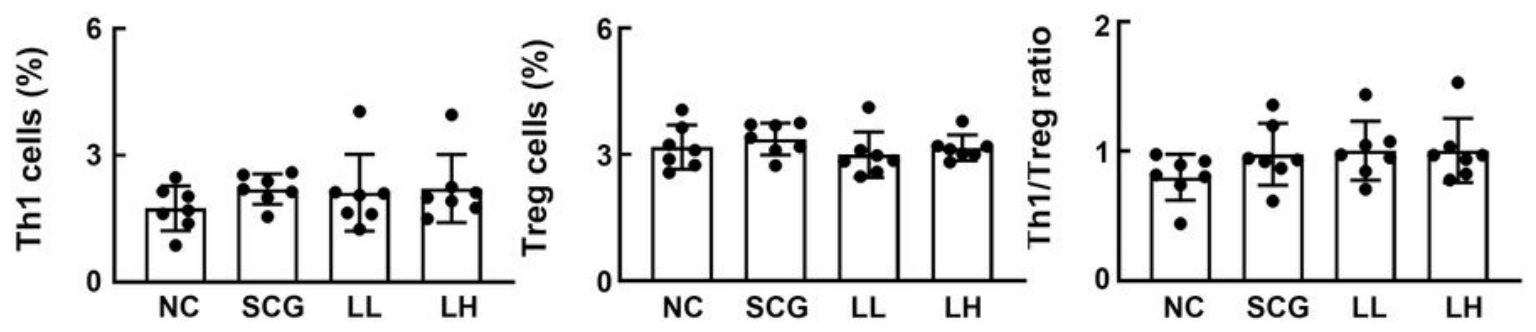

(C)

(a)

(b)

(c)
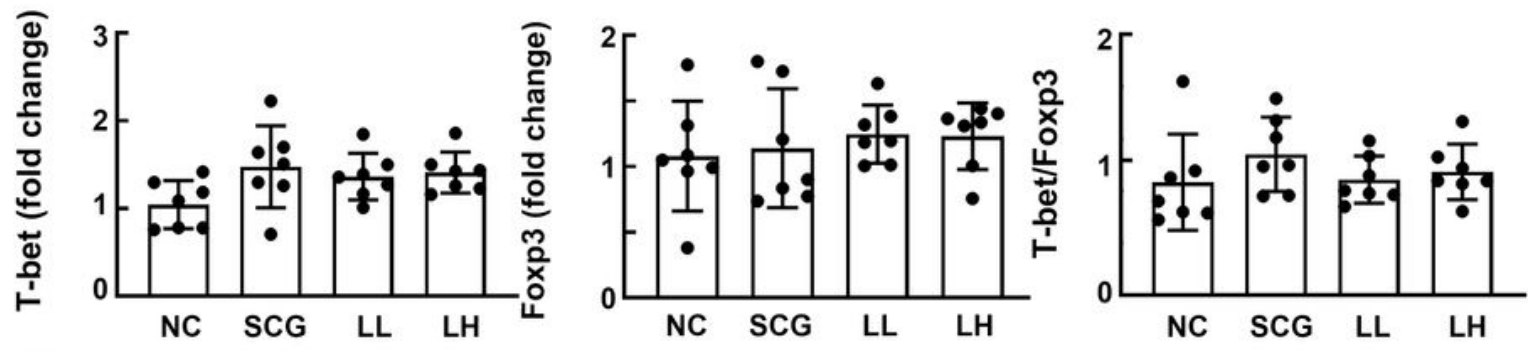

(D)

(a)

(b)

(c)
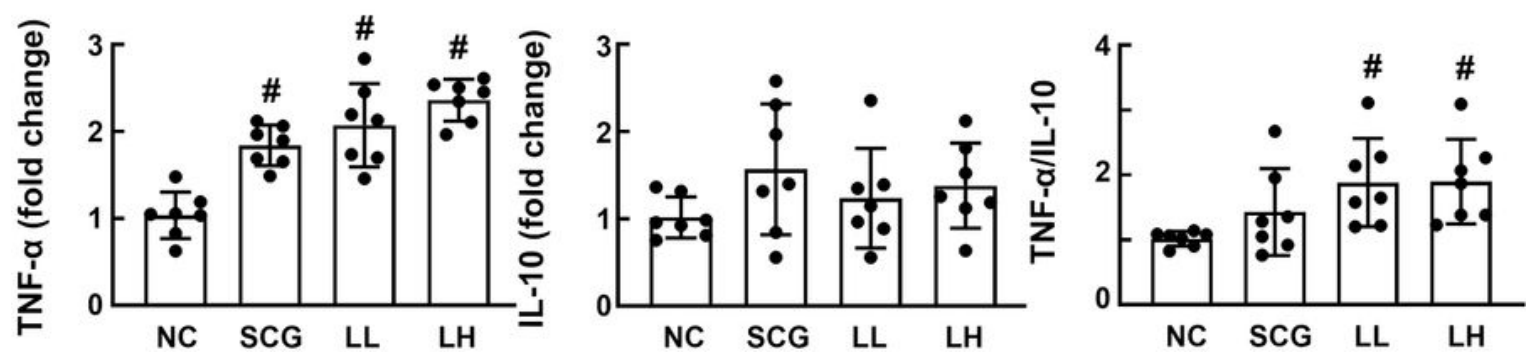

Figure 2 
Effect of HDB1258 and Saccharomyces cerevisiae (SC) $\beta$-glucan on splenic NK cell cytotoxicity, peritoneal macrophage phagocytosis, fecal IgA level, splenic Th1 and Treg cell differentiation, splenic Tbet, Foxp3, TNF-a, and IL-10 expression in mice. (A) Effects on splenic NK cell cytotoxicity (a), peritoneal macrophage phagocytosis (b), and fecal IgA level (c). (B) Effects on the differentiation of Th1 (a) and Treg cells (b) and ratio of Th1 to Treg cells (c). Effects on the expression of T cell transcription factors Tbet (a) and Foxp3 (b) and ratio of T-bet to Foxp3 expression (c). Effects on the expression of TNF-a (a) and IL-10 (b) and ratio of TNF-a to IL-10 expression. HDB1258 (LL, 1×108 CFU/mouse/day and LH, $1 \times 109 \mathrm{CFU} / \mathrm{mouse} /$ day) or SC $\beta$-glucan (SCG, $50 \mathrm{mg} / \mathrm{kg} /$ day) was orally gavaged daily for 14 days. Normal control mice (CON) were treated with vehicle (saline) instead of test agents. Data values were described as mean $\pm S D(n=6)$. ${ }^{\star} p<0.05$ vs. CON.

(a)

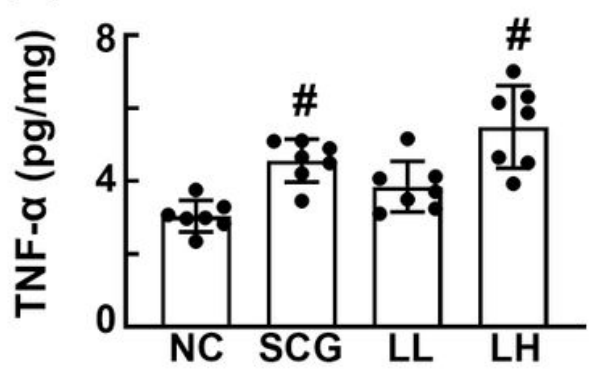

(d)

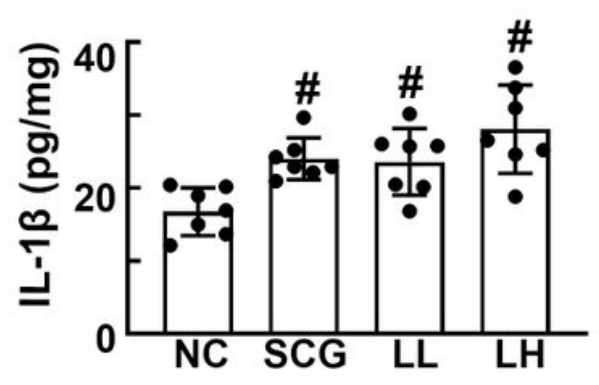

(e)

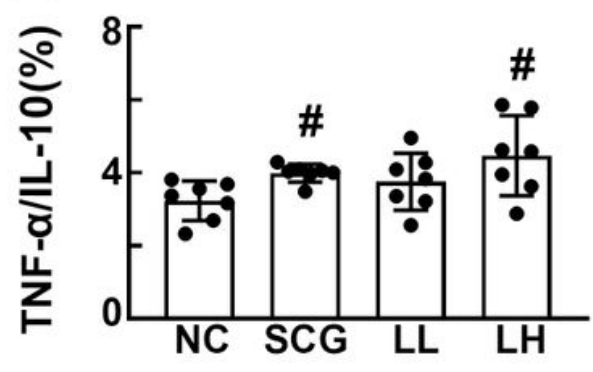

(b)

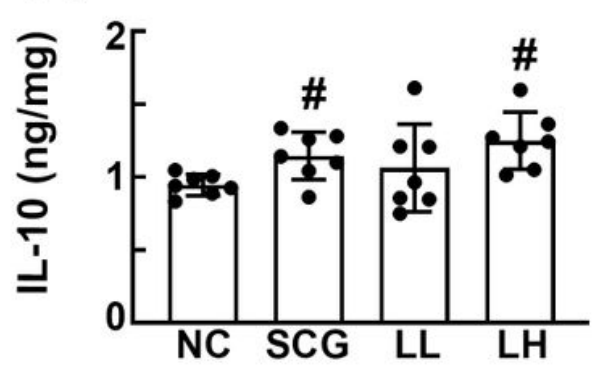

(f)

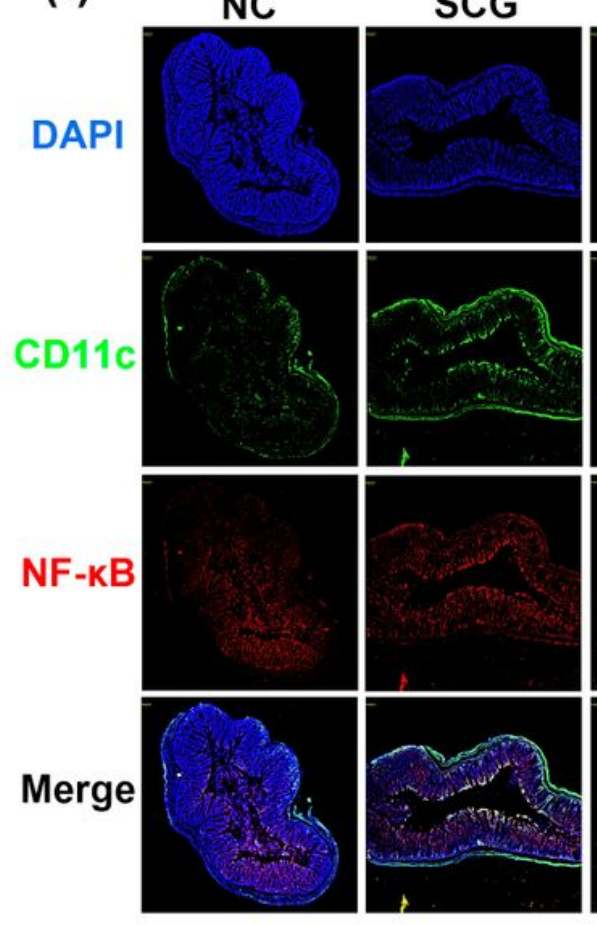

(c)

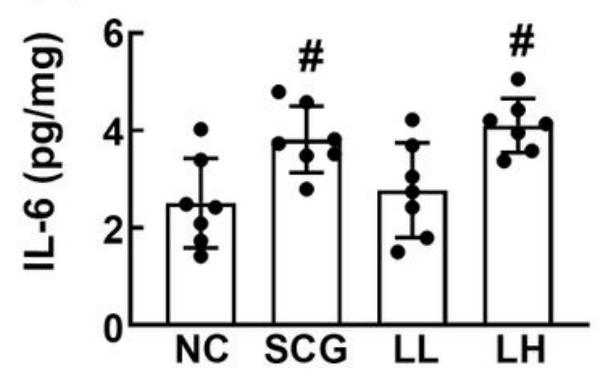

LL
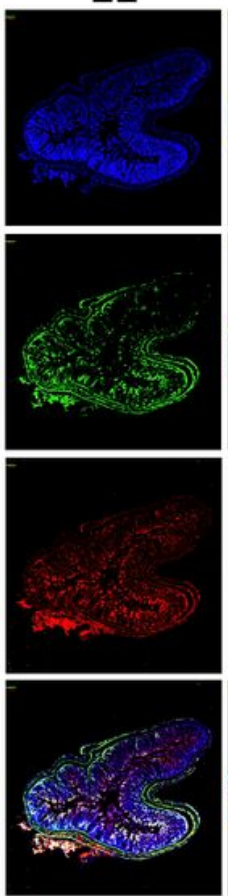

LH

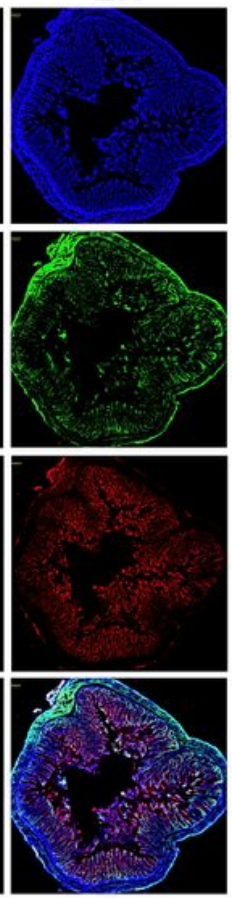

Figure 3

Effect of HDB1258 and SC $\beta$-glucan on the TNF- $\alpha$ (a), IL-10 (b), IL-6 (c), and IL- $1 \beta$ expression (d), ratio of TNF-a to IL-10 expression (e), and NF-KB+CD11c+ cell population ( $f$ ) in the colon of mice. HDB1258 (LL, $1 \times 108 \mathrm{CFU} / \mathrm{mouse} /$ day and LH, $1 \times 109 \mathrm{CFU} /$ mouse/day) or SC $\beta$-glucan (SCG, $50 \mathrm{mg} / \mathrm{kg} /$ day) was orally 

agents. Data values were described as mean $\pm S D(n=6)$. Means with same letters are not significantly different $(p<0.05)$.

(A)

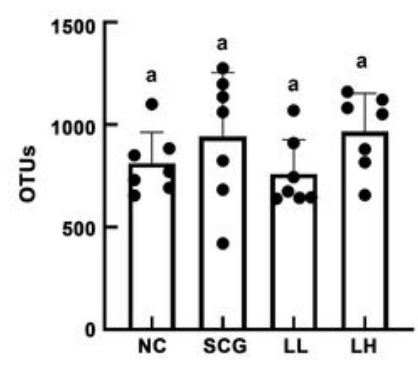

(D) (a)
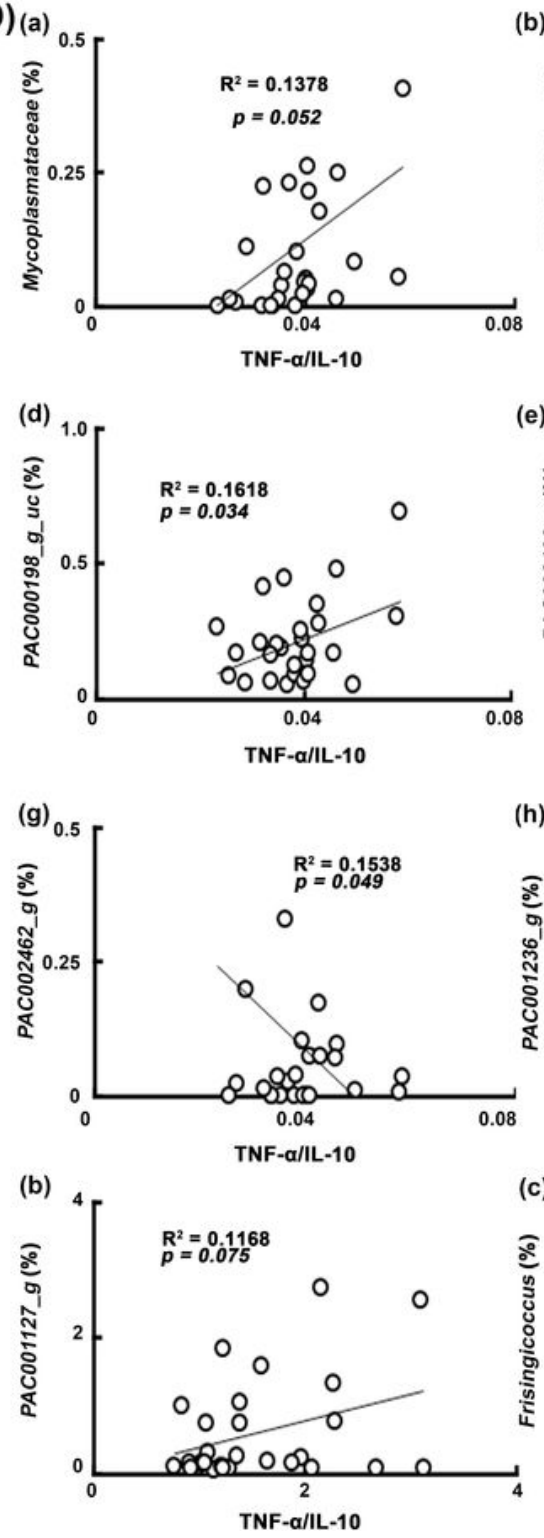

(B)

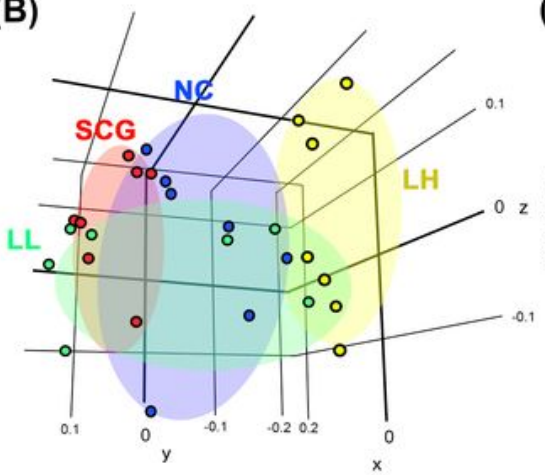

(b)

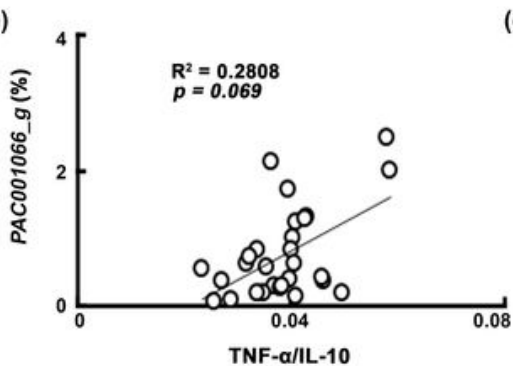

(C)

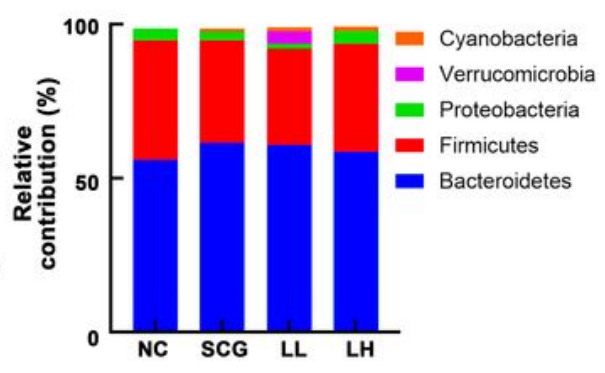

(c)

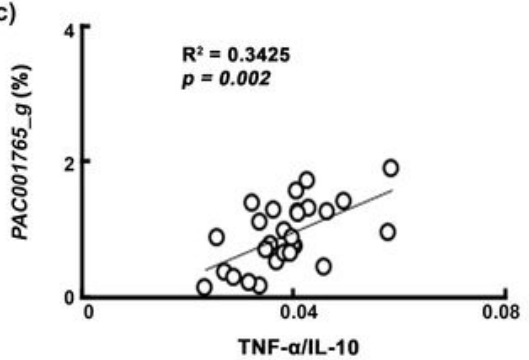

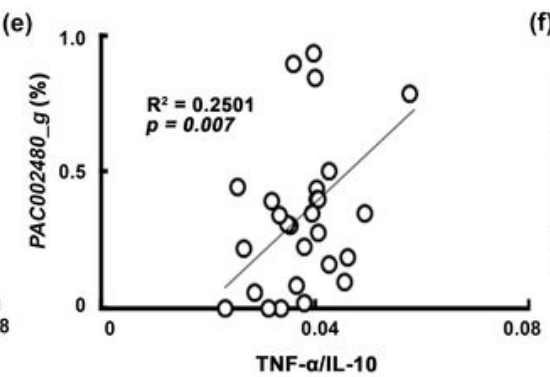
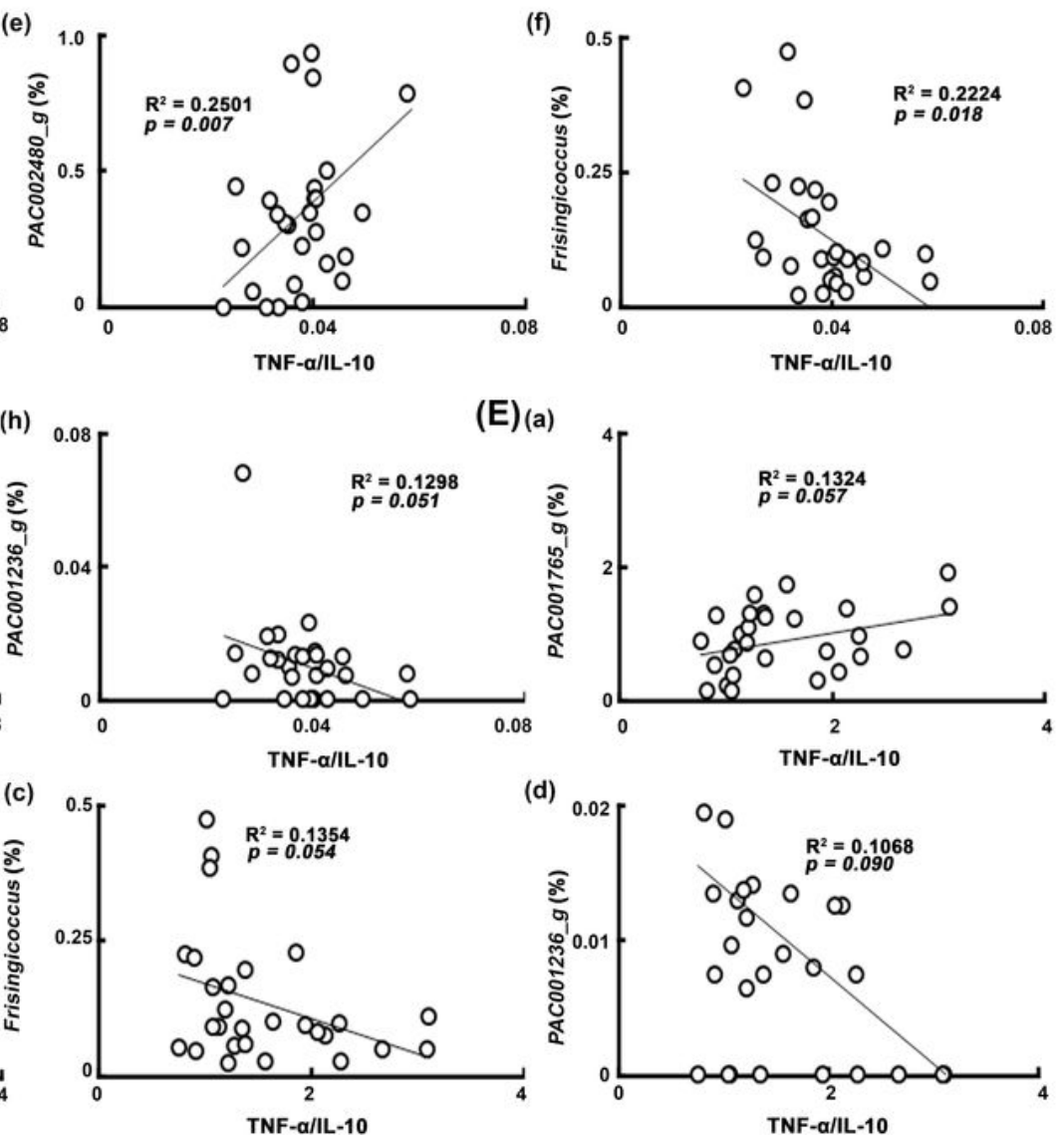

Figure 4

Effect of HDB1258 and SC $\beta$-glucan on the gut microbiota composition in mice. (A) Effects on a-diversity (OUT richness). (B) Effects on $\beta$-diversity. (C) Effects on the gut bacteria composition at the phylum level. 
(D) The correlation between gut microbiota (at the family and genus levels) and ratio of TNF-a to IL-10 expression in the colon. (E) The correlation between gut microbiota (at the family and genus levels) and TNF-a to IL-10 expression ratio in the spleen. HDB1258 (LL, 1×108 CFU/mouse/day and LH, $1 \times 109$ $\mathrm{CFU} / \mathrm{mouse} /$ day) or SC $\beta$-glucan (SCG, $50 \mathrm{mg} / \mathrm{kg} /$ day) was orally gavaged daily for 14 days. Normal control group (CON) was treated with saline instead of test agents. Data values were described as mean $\pm \operatorname{SD}(n=6) .{ }^{*} p<0.05$ vs. CON.

(A)

(a)

(b)

(c)
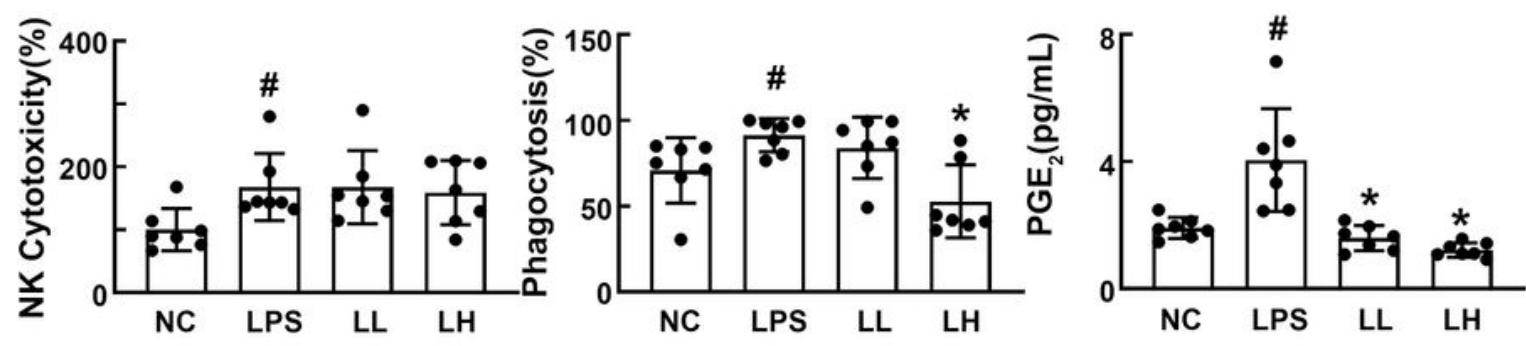

(B)

(a)

(b)

(c)

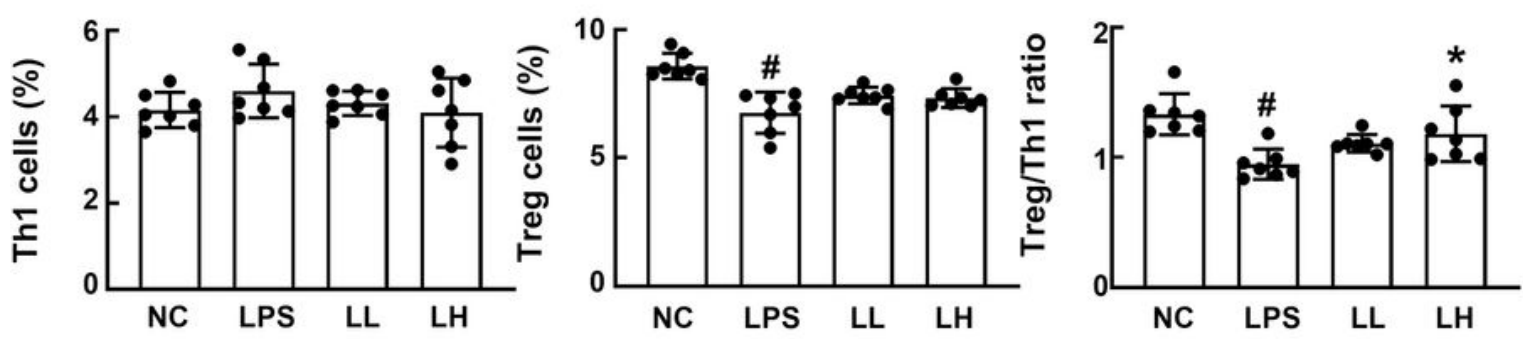

(C)

(a)

(b)

(c)
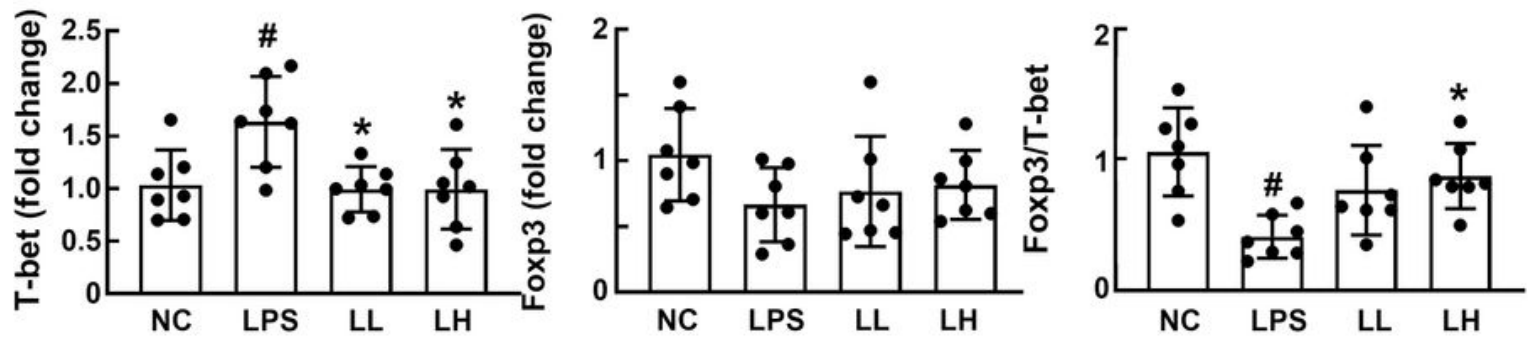

(D)

(a)

(b)

(c)
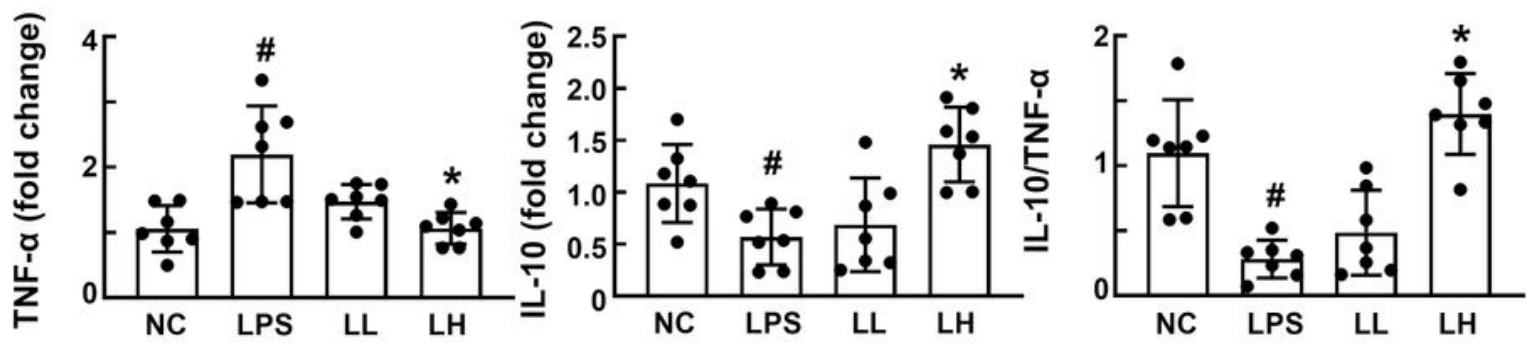

Figure 5 
Effect of HDB1258 on splenic NK cell cytotoxicity, peritoneal macrophage 629 phagocytosis, blood PGE2 level, splenic Th1 and Treg cell differentiation, splenic T-bet, Foxp3, TNF-a, and IL-10 expression in mice with LPS-induced systemic inflammation. (A) Effects on splenic NK cell cytotoxicity (a), peritoneal macrophage phagocytosis (b), and blood PGE2 level (c). (B) Effects on the differentiation of Th1 (a) and Treg cells (b) and ratio of Th1 to Treg cells (c). Effects on the expression of T cell transcription factors Tbet (a) and Foxp3 (b) and ratio of T-bet to Foxp3 expression (c). Effects on the expression of TNF-a (a) and IL-10 (b) and ratio of TNF-a to IL-10 expression. Mice was interaperitoneally injected with LPS (10 $\mu \mathrm{g} / \mathrm{kg} /$ day) for 10 days. HDB1258 (LPS, vehicle; LL, $1 \times 108 \mathrm{CFU} /$ mouse/day and LH, $1 \times 109$ $\mathrm{CFU} /$ mouse/day) was orally gavaged daily for 14 days from the final injection of LPS. Normal control mice (CON) were treated with saline instead of LPS and test agents. Data values were described as mean $\pm S D(n=6) . \# p<0.05$ vs. CON. ${ }^{*} p<0.05$ vs. group treated with LPS alone.

(a)

들
$\frac{5}{0}$
ฮ
응
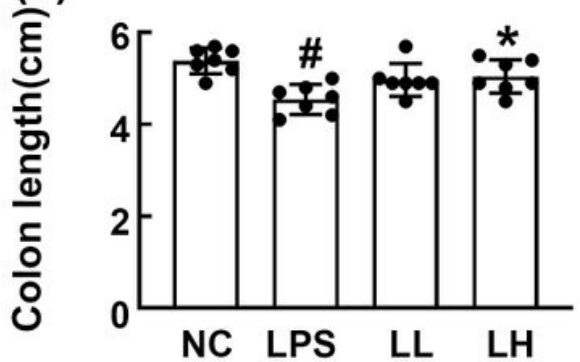

(d)

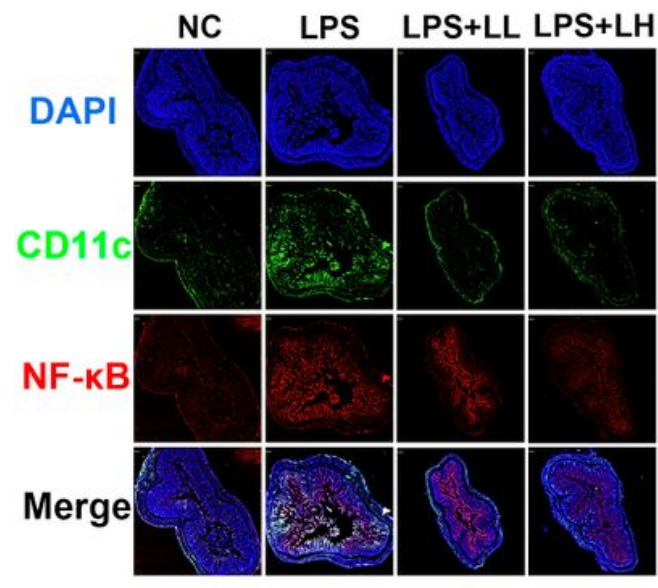

(e)

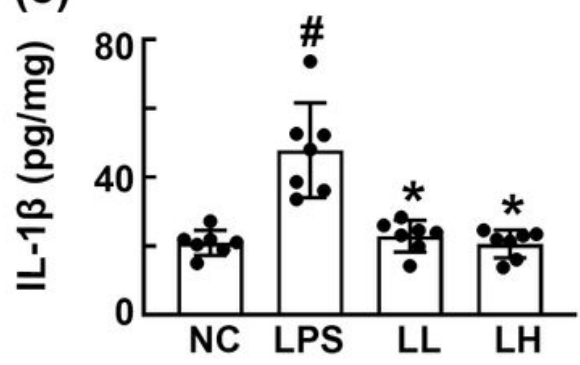

(g)

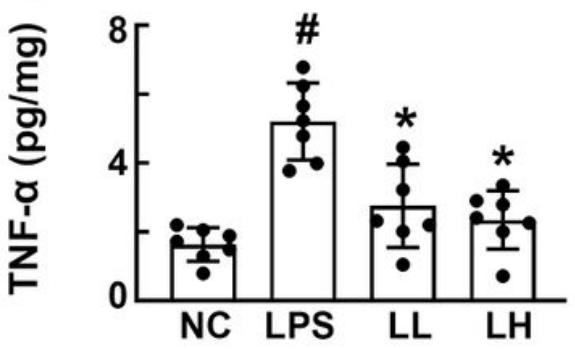

(b)

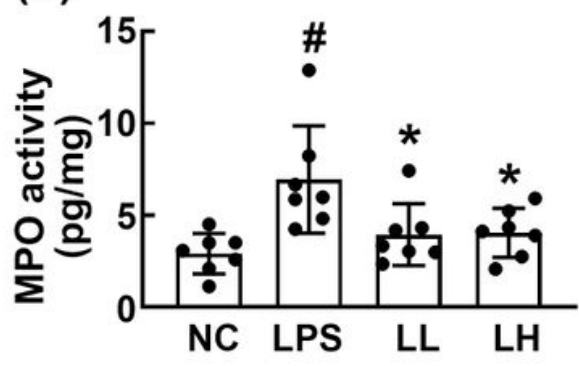

(h)

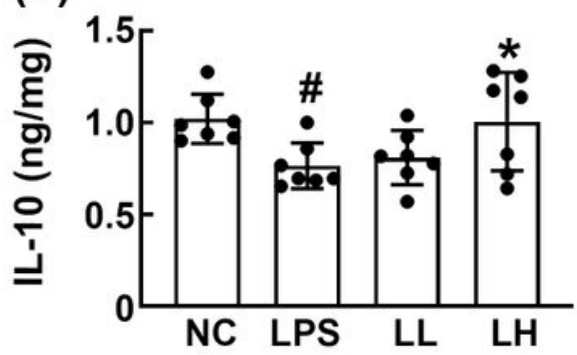

(c)

$\beta$-actin

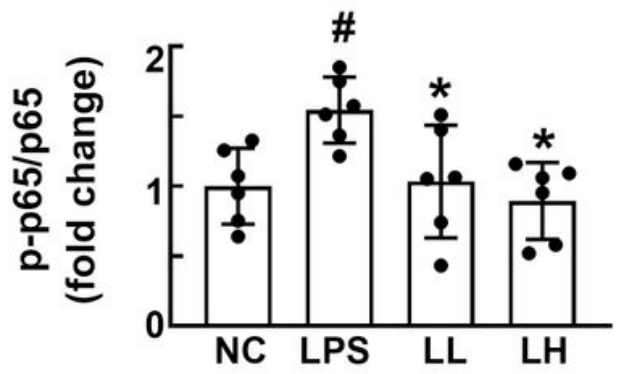

P-P65

P65

NC LPS LPS+LL LPS+LH

(f)

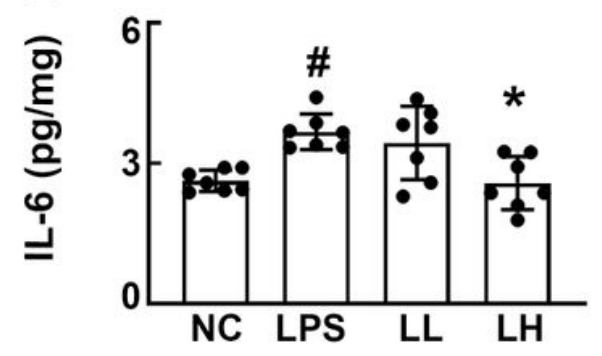

(i)
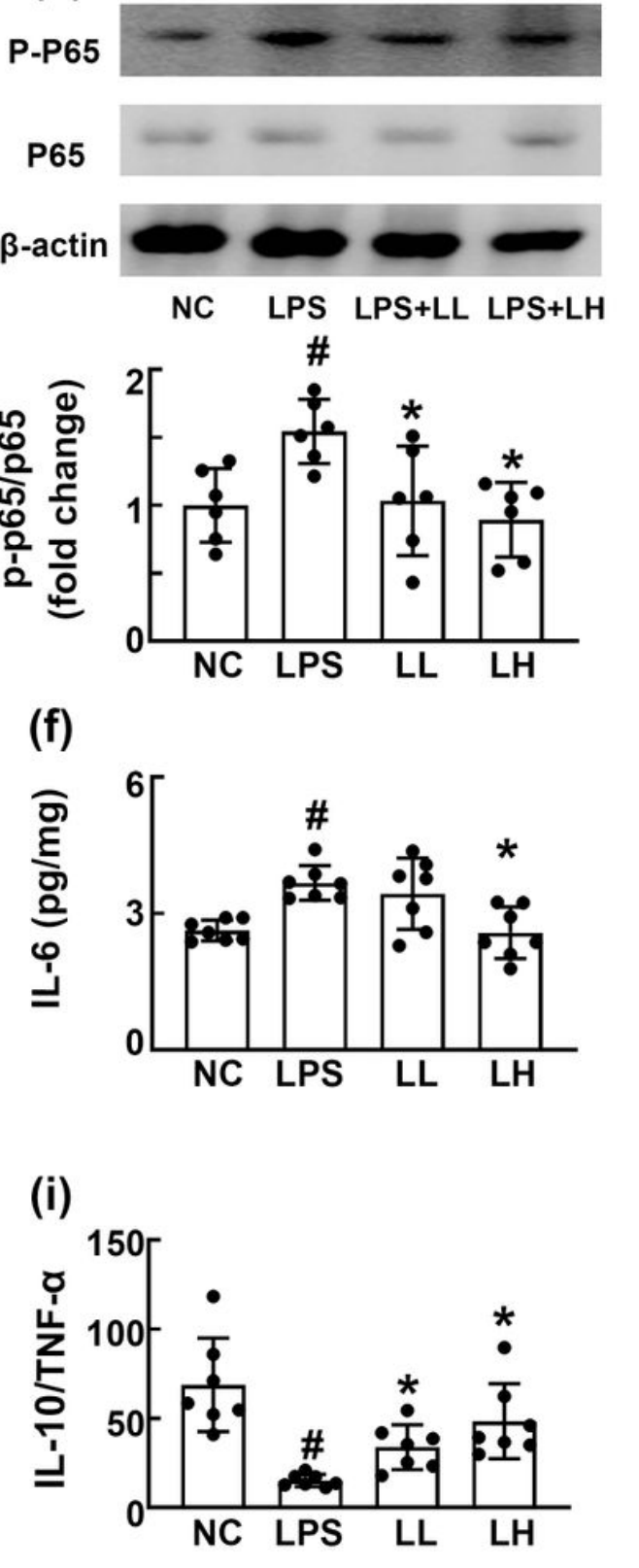

Figure 6 
Effect of HDB1258 on the LPS-induced colitis in mice with LPS-induced systemic inflammation. on the colon length (a), myeloperoxidase (MPO) activity (b), IL-1 1 (c), IL-6 (d), TNF-a (e), and IL-10 expression (f), ratio of IL-10 to TNF-a expression (g), and NF-KB+CD11c+ cell population (h). Mice was intraperitoneally injected with LPS (10 $\mu \mathrm{g} / \mathrm{kg} /$ day) for 10 days. HDB1258 (LPS, vehicle; LL, $1 \times 108 \mathrm{CFU} / \mathrm{mouse} /$ day and LH, $1 \times 109 \mathrm{CFU} /$ mouse/day) was orally gavaged daily for 14 days from the final injection of LPS. Normal control mice (CON) were treated with saline instead of LPS and test agents. Data values were described as mean $\pm S D(n=6)$. \#p $<0.05$ vs. CON. * $p<0.05$ vs. group treated with LPS alone.

(A)

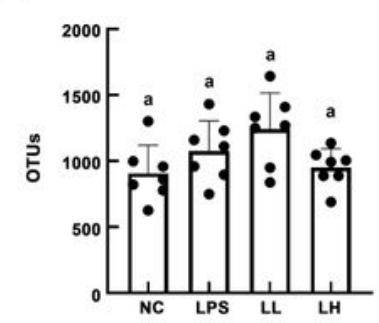

(B)

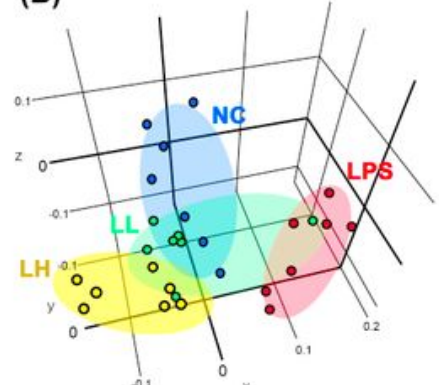

(C)

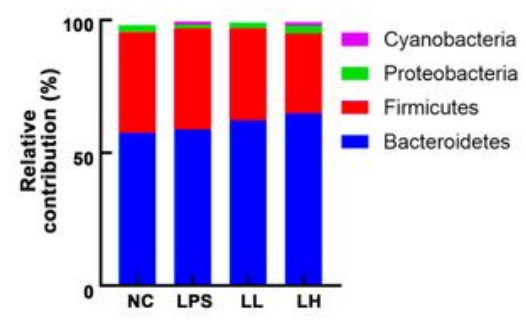

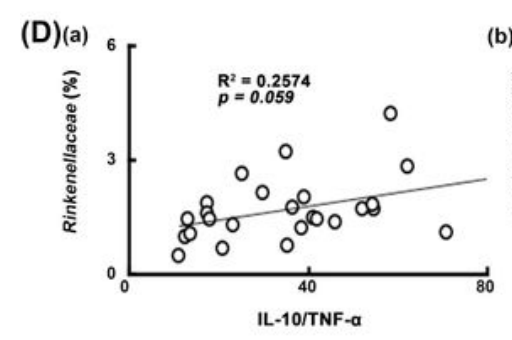
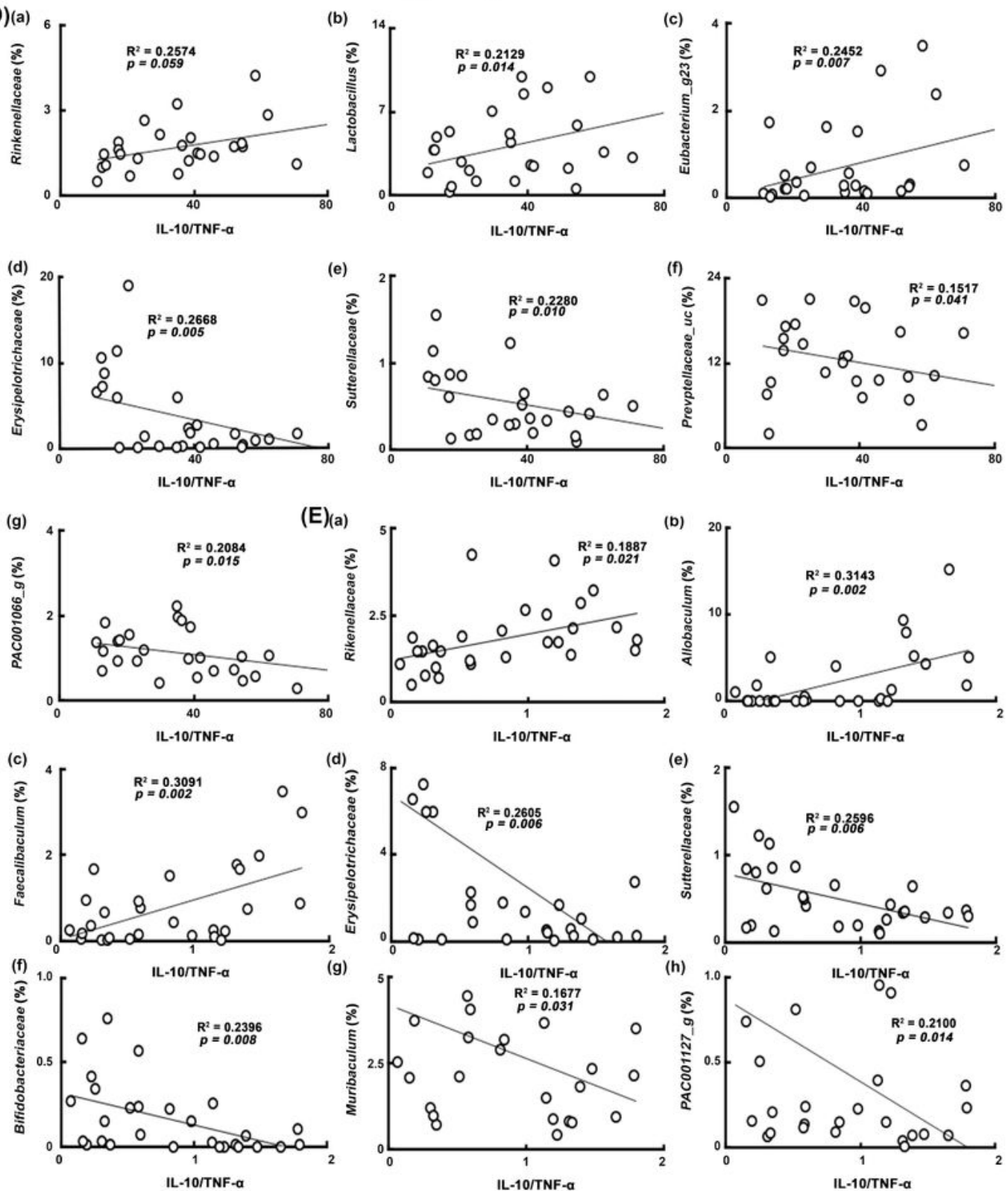


\section{Figure 7}

Effect of HDB1258 on the composition of gut microbiota in mice with LPS-652 induced systemic inflammation. (A) Effects on a-diversity (OUT richness). (B) Effects on $\beta$-diversity. (C) Effects on the gut bacteria composition at the phylum level. (D) The correlation between gut microbiota (at the family and genus levels) and ratio of IL-10 to TNF-a expression in the colon. (E) The correlation between gut microbiota (at the family and genus levels) and ratio of IL-10 to TNF-a expression in the spleen. Mice was intraperitoneally injected with LPS (10 $\mu \mathrm{g} / \mathrm{kg} /$ day) for 10 days. HDB1258 (LPS, vehicle; LL, 1×108 Effect of HDB1258 on the composition of gut microbiota in mice with LPS-652 induced systemic inflammation. (A) Effects on a-diversity (OUT richness). (B) Effects on $\beta$-diversity. (C) Effects on the gut bacteria composition at the phylum level. (D) The correlation between gut microbiota (at the family and genus levels) and ratio of IL-10 to TNF-a expression in the colon. (E) The correlation between gut microbiota (at the family and genus levels) and ratio of IL-10 to TNF- $a$ expression in the spleen. Mice was intraperitoneally injected with LPS (10 $\mu \mathrm{g} / \mathrm{kg} /$ day) for 10 days. HDB1258 (LPS, vehicle; LL, 1×108

\section{Supplementary Files}

This is a list of supplementary files associated with this preprint. Click to download.

- BMCmicrobiologysupplementaryinformation1.pdf 